\title{
Voltage-energized Calcium-sensitive ATP Production by Mitochondria
}

\author{
Andrew P. Wescott ${ }^{1,2}$, Joseph P. Y. Kao ${ }^{1,2}$, W. Jonathan Lederer ${ }^{1,2}$, Liron Boyman ${ }^{1,2,{ }^{*}}$ \\ ${ }^{1}$ Center for Biomedical Engineering and Technology, University of Maryland School of Medicine, \\ Baltimore, MD 21201, USA. \\ 2Department of Physiology, University of Maryland School of Medicine, Baltimore, Maryland \\ 21201, USA.
}

\section{Abstract}

Regulation of ATP production by mitochondria, critical to multicellular life, is poorly understood. Here we investigate the molecular controls of this process in heart and provide a framework for its $\mathrm{Ca}^{2+}$-dependent regulation. We find that the entry of $\mathrm{Ca}^{2+}$ into the matrix through the mitochondrial calcium uniporter (MCU) in heart has neither an apparent cytosolic $\mathrm{Ca}^{2+}$ threshold nor gating function and guides ATP production by its influence on the inner mitochondrial membrane (IMM) potential, $\Delta \Psi_{\mathrm{m}}$. This regulation occurs by matrix $\mathrm{Ca}^{2+}$-dependent modulation of pyruvate and glutamate dehydrogenase activity and not through any effect of $\mathrm{Ca}^{2+}$ on ATP Synthase or on Electron Transport Chain Complexes II, III or IV. Examining the $\Delta \Psi_{\mathrm{m}}$ dependence of ATP production over the range of $-60 \mathrm{mV}$ to $-170 \mathrm{mV}$ in detail reveals that cardiac ATP synthase has a voltage dependence that distinguishes it fundamentally from the previous standard, the bacterial ATP synthase. Cardiac ATP synthase operates with a different $\Delta \Psi_{\mathrm{m}}$ threshold for ATP production than bacterial ATP synthase and reveals a concave-upwards shape without saturation. Skeletal muscle MCU $\mathrm{Ca}^{2+}$ flux, while also having no apparent cytosolic $\mathrm{Ca}^{2+}$ threshold, is substantially different from the cardiac MCU, yet the ATP synthase voltage dependence in skeletal muscle is identical to that in the heart. These results suggest that while the conduction of cytosolic $\mathrm{Ca}^{2+}$ signals through the MCU appears to be tissue-dependent, as shown by earlier work ${ }^{1}$, the control of ATP synthase by $\Delta \Psi_{\mathrm{m}}$ appears to be broadly consistent among tissues but is clearly different from bacteria.

Reprints and permissions information is available at www.nature.com/reprints.Users may view, print, copy, and download text and data-mine the content in such documents, for the purposes of academic research, subject always to the full Conditions of use:http:// www.nature.com/authors/editorial_policies/license.html\#terms

*Correspondence and requests for materials should be addressed to L.B. (lboyman@som.umaryland.edu).

Present addresses: Center for Biomedical Engineering and Technology, University of Maryland School of Medicine, 111 S. Penn Street. Baltimore, Maryland 21201 USA.

Author Contributions

A.P.W. and L.B. were involved with all experiments, data collection, and data analysis; A.P.W., L.B., and W.J.L. contributed to study design, data interpretation, and writing the paper; J.P.Y. K. synthesized the 4-armed PEG-boronic acid and the diAM-succinate; All authors edited the manuscript.

Supplementary Information is linked to the online version of the paper at www.nature.com/nature.

Competing Interests Statement

The authors declare no competing financial interests. 
ATP consumption in heart is the highest of any tissue and, even with the phosphocreatine regenerating system, the ATP reserve is minimal - lasting less than 1 minute if ATP production were to be stopped instantaneously ${ }^{2,3}$. It is thus not surprising that mitochondria, the primary source of ATP production, play an important role in cardiovascular physiology and pathophysiology ${ }^{4}$. Mitochondria are similarly important in other high-energyconsuming tissues such as brain, kidney, liver and skeletal muscle ${ }^{5,6}$. Despite the critical importance of mitochondria in producing ATP, there is little time-resolved quantitative data on how mitochondria work ${ }^{7,8}$. Here we provide quantitative information on how cardiac mitochondria generate ATP, how ATP production is powered by $\Delta \Psi_{\mathrm{m}}$, and how $\Delta \Psi_{\mathrm{m}}$ is regulated by $\mathrm{Ca}^{2+}$ concentration in the mitochondrial matrix $\left(\left[\mathrm{Ca}^{2+}\right]_{\mathrm{m}}\right)$.

Fig. 1a-b show surface plots of ATP production measured as functions of $\left[\mathrm{Ca}^{2+}\right]_{\mathrm{m}}$ and the added concentrations of ADP ([ADP]). Fluorescence $\left[\mathrm{Ca}^{2+}\right]_{\mathrm{m}}$ and luminescence ATP measurements were performed together from isolated heart mitochondria and quantitatively calibrated in each test condition (Extended Data Figs. 1-3). These data show that elevated $[\mathrm{ADP}]$ and $\left[\mathrm{Ca}^{2+}\right]_{\mathrm{m}}$ robustly stimulate ATP production (Fig. 1a-e), with a half-activation concentration of $\sim 20 \mu \mathrm{M}$ for [ADP] (Fig. $1 \mathrm{~g}$ ) and $\sim 600 \mathrm{nM}$ for $\left[\mathrm{Ca}^{2+}\right]_{\mathrm{m}}$ (Fig.1d-f). ADP and $\left[\mathrm{Ca}^{2+}\right]_{\mathrm{m}}$ work by different mechanisms. Elevated $[\mathrm{ADP}]$ increases the ADP flux into the mitochondrial matrix, mediated by the adenine nucleotide translocase (ANT), thus increasing substrate availability for the ATP synthase to augment ATP production ${ }^{9,10}$ (also see Supplemental Discussion 2.1). On the other hand, increasing the steady-state availability of inorganic phosphate $\left(\mathrm{P}_{\mathrm{i}}\right)$ from $1 \mathrm{mM}$ (physiological) to $10 \mathrm{mM}$ (super-physiological) diminished ATP production (Fig. 1b, 1f and 1g). Fig. 1c shows the absolute value of the difference. These results are the first determination of the dependence of ATP production on the three key variables, $\left[\mathrm{Ca}^{2+}\right]_{\mathrm{m}},[\mathrm{ADP}]$ and $\left[\mathrm{P}_{\mathrm{i}}\right]$, and provide an important context for additional physiologic investigations.

The above findings (Figs. 1a-1g) demonstrate regulation of ATP production by $\left[\mathrm{Ca}^{2+}\right]_{\mathrm{m}}$, but shed no light on the mechanisms. Fig. 1h-l present experiments designed to identify the nodes of $\mathrm{Ca}^{2+}$ regulation: they probe the $\left[\mathrm{Ca}^{2+}\right]_{\mathrm{m}}$ sensitivity of ATP production powered by diverse metabolic substrates. We examined different carbon sources such as carbohydrates and amino acids that are metabolized through the tricarboxylic acid cycle (TCA cycle). We also examined lipids, which undergo catabolic steps in the mitochondrial matrix - they only enter the TCA cycle after $\beta$-oxidation, during which they regenerate abundant NADH and $\mathrm{FADH}_{2}$ and are broken down to acetyl-CoA and succinyl-CoA. We have identified specific carbon substrates that enable the $\left[\mathrm{Ca}^{2+}\right]_{\mathrm{m}}$-sensitive ATP production and other that do not (Fig. 1j-1). The extensive mitochondrial literature makes no such differentiation between mitochondrial substrates, and regards mitochondrial ATP production as $\mathrm{Ca}^{2+}$ dependent in general (see Supplemental Discussion 2.2-2.3). Our findings show that the entry of glutamate and pyruvate into the TCA cycle is regulated by $\left[\mathrm{Ca}^{2+}\right]_{\mathrm{m}}$, and it is through this regulation that increasing $\left[\mathrm{Ca}^{2+}\right]_{\mathrm{m}}$ augments ATP production. Glutamate and pyruvate are the metabolic products of amino acids and carbohydrates. Our findings thus identify $\left[\mathrm{Ca}^{2+}\right]_{\mathrm{m}}$ as key in regulating mitochondrial utilization of carbohydrates and amino acids. These findings are consistent with predictions made by earlier work with purified mitochondrial dehydrogenases ${ }^{11,12}$. Our results, however, supported by NADH measurements (Extended Data Figs. 1d), contradict other published predictions. Our results 
indicate that neither b-oxidation (of lipids) nor complexes II, III, IV or V (ATP synthase) are significantly regulated by $\left[\mathrm{Ca}^{2+}\right]_{\mathrm{m}}$ despite arguments to the contrary ${ }^{13,14}$ (see Supplemental Discussion 2.2-2.3).

Sensitivity to $\left[\mathrm{Ca}^{2+}\right]_{\mathrm{m}}$ enables ATP production to ramp up with elevated cellular workload. To test the physiological impact of the $\left[\mathrm{Ca}^{2+}\right]_{\mathrm{m}}$ sensitivity on ATP production we examined $\Delta \Psi_{\mathrm{m}}$ in cardiac myocytes under conditions where they are electrically and mechanically active (see Supplementary Video. 1). We provided specific carbon substrates that enable $\left[\mathrm{Ca}^{2+}\right]_{\mathrm{m}}$-sensitive ATP production (pyruvate), and also substrates that support high-rate ATP production that is insensitive to $\left[\mathrm{Ca}^{2+}\right]_{\mathrm{m}}$ (i.e., membrane-permeant diAM-succinate in combination with rotenone to block ETC Complex I, see Fig. 1k). We first examined the effect of pyruvate on changes in $\Delta \Psi_{\mathrm{m}}$ when a single cardiac cell is integrated into an optically clear but mechanically resistive poly(vinyl alcohol) (PVA) hydrogel (Fig. 1m-o) ${ }^{15}$. The cell was mechanically coupled to the hydrogel by attaching its surface carbohydrates (glycans) to the hydrogel through a 4-armed PEG-boronic acid crosslinker (Fig. 1o; chemical synthesis in Methods section and Extended Data Fig. 4). Attachment to the PVA gel significantly increased the mechanical load on the cell. The cell stimulation frequency was increased from 1 to $8 \mathrm{~Hz}$. Notably, despite increased ATP consumption at $8 \mathrm{~Hz}$, there was no change in $\Delta \Psi_{\mathrm{m}}$ when metabolic substrates that impart $\mathrm{Ca}^{2+}$-sensitivity on ATP production were present (pyruvate). This suggests that when $\Delta \Psi_{\mathrm{m}}$ was being maintained by NADH production through $\mathrm{Ca}^{2+}$-sensitive metabolism, the electron transport chain (ETC) could keep $\Delta \Psi_{\mathrm{m}}$ hyperpolarized (also see Extended Data Fig. 1d). In stark contrast, $\Delta \Psi_{\mathrm{m}}$ depolarized during elevated workload when we supplied substrates that support ATP production that is not boosted by $\left[\mathrm{Ca}^{2+}\right]_{\mathrm{m}}$ (diAM-succinate + rotenone). With these substrates present, upon return to low workload conditions, the rate of $\Delta \Psi_{\mathrm{m}}$ depolarization subsides (Fig. 1q-r). These findings indicate that at elevated workload only $\mathrm{Ca}^{2+}$-dependent ATP production is sustainable and does not result in a decline of $\Delta \Psi_{\mathrm{m}}$.

While these findings (Figs. $1 \mathrm{~m}-1 \mathrm{~s}$ ) suggest that $\left[\mathrm{Ca}^{2+}\right]_{\mathrm{m}}$ plays a major physiological role in regulating $\Delta \Psi_{\mathrm{m}}$, they shed no light on the quantitative relationship between the three critical components of ATP production - ADP (the substrate), $\mathrm{Ca}^{2+}$ (the regulator), and $\Delta \Psi_{\mathrm{m}}$ (the energy source). These relationships are investigated under conditions where they can be controlled or measured quantitatively using isolated cardiac mitochondria. Our findings are shown in the surface plot in Fig. 2a. The value of $\Delta \Psi_{\mathrm{m}}$ mapped in the surface plot represents the points of balance between ETC proton efflux and proton influx via ATP synthase and any other pathway such as the ANT. ATP synthase consumes energy stored in $\Delta \Psi_{\mathrm{m}}$ by coupling proton influx to the conversion of ADP to ATP ${ }^{16}$. ANT consumes energy stored in $\Delta \Psi_{\mathrm{m}}$ to exchange ADP with ATP. In the absence of extra-mitochondrial ADP (and hence in the absence of mitochondrial ADP), ATP synthase does not produce ATP and does not consume energy (i.e., there is no proton influx). Under this condition, $\Delta \Psi_{\mathrm{m}}$ is stable and energized at about $-170 \mathrm{mV}$. However, when extra-mitochondrial [ADP] is elevated to 500 $\mu \mathrm{M}$, ATP production is strongly stimulated. Under the same condition, if $\left[\mathrm{Ca}^{2+}\right]_{\mathrm{m}}$ is very low $\left(<200 \mathrm{nM}\right.$ ), then the ATP production leads to significant depolarization of $\Delta \Psi_{\mathrm{m}}$ to about $-120 \mathrm{mV}$. However, with an elevated $\left[\mathrm{Ca}^{2+}\right]_{\mathrm{m}}(\sim 3 \mu \mathrm{M})$ to stimulate NADH production, the same $500 \mu \mathrm{M}[\mathrm{ADP}]$ increases ATP production with a more energetic $\Delta \Psi_{\mathrm{m}}$ of $-145 \mathrm{mV}$ (Fig. 2a-b). From these data, higher [ADP] augments ATP production but causes 
depolarization of $\Delta \Psi_{\mathrm{m}}$, with half-maximal depolarization occurring at [ADP] $\approx 12 \mu \mathrm{M}$ (Fig. 2c). This depolarization is significantly counteracted by an increase in $\left[\mathrm{Ca}^{2+}\right]_{\mathrm{m}}$, with a halfmaximal activation at $\left[\mathrm{Ca}^{2+}\right]_{\mathrm{m}} \approx 500 \mathrm{nM}$ (Fig. 2d). Thus, our findings demonstrate that the $\left[\mathrm{Ca}^{2+}\right]_{\mathrm{m}}$-sensitive processes that support the utilization of energy in carbon sources to regenerate $\mathrm{NADH}^{13,14,17}$ stimulate higher proton efflux by the ETC and produce a more hyperpolarized $\Delta \Psi_{\mathrm{m}}$. We find that this effect of $\left[\mathrm{Ca}^{2+}\right]_{\mathrm{m}}$ on $\Delta \Psi_{\mathrm{m}}$ develops gradually (seconds) and does not follow fast changes in $\left[\mathrm{Ca}^{2+}\right]_{\mathrm{m}}$ (see Extended Data Fig. 5). Importantly, over the full range of the $\left[\mathrm{Ca}^{2+}\right]_{\mathrm{m}}$ - and ADP-regulated ATP production as mapped in Fig. 1a and Fig. 2a, there is no significant change in $\mathrm{pH}_{\mathrm{m}}$, as shown in Fig. 2e-g. Under these same conditions there is an approximately 30-fold change of $\left[\mathrm{Ca}^{2+}\right]_{\mathrm{m}}$, a 20 -fold change of [ADP], a 1.5-fold change in $\Delta \Psi_{\mathrm{m}}$, leading to a 3 -fold change of ATP production. These observations suggest that although proton movement across the inner membrane enables the ATP synthase to work, $\Delta \Psi_{\mathrm{m}}$ itself is the critical regulator of ATP production. Taken together, Fig. 2 shows the importance of $\left[\mathrm{Ca}^{2+}\right]_{\mathrm{m}}$ in enhancing NADH generation, which is critical in keeping $\Delta \Psi_{\mathrm{m}}$ hyperpolarized without material influence on $\mathrm{pH}_{\mathrm{m}}$.

Next, we investigate how physiological activity leads to changes of $\left[\mathrm{Ca}^{2+}\right]_{\mathrm{m}}$. First, we examine the movement of cytosolic $\mathrm{Ca}^{2+}$ into the mitochondrial matrix. $\left[\mathrm{Ca}^{2+}\right]_{\mathrm{m}}$ increases when $\mathrm{Ca}^{2+}$ enters the mitochondria through the MCU channel in the inner mitochondrial membrane, the only known route of mitochondrial $\mathrm{Ca}^{2+}$ influx ${ }^{1,18-22}$. By this route, as $\left[\mathrm{Ca}^{2+}\right]_{\mathrm{i}}$ increases to trigger contraction in heart, it also enters the matrix through MCU and thereby elevates $\left[\mathrm{Ca}^{2+}\right]_{\mathrm{m}}$ which, as we saw in Fig.1, boosts ATP production. Measurements of MCU-mediated $\mathrm{Ca}^{2+}$ influx into the cardiac mitochondrial matrix under physiological conditions are shown in Figs. 3a-d. Measuring $\mathrm{Ca}^{2+}$ influx quantitatively at high temporal resolution is challenging at physiological $\left[\mathrm{Ca}^{2+}\right]_{\mathrm{i}}$ because MCUs are sparse (15-65 per cardiac mitochondrion ${ }^{1}$ ) and have low single-channel conductance $(\sim 0.1 \mathrm{fS}$ at $500 \mathrm{nM}$ $\left[\mathrm{Ca}^{2+}\right]_{\mathrm{i}}$ and $\Delta \Psi_{\mathrm{m}}=-160 \mathrm{mV}$, see Methods and Williams et. al., 2013). Nevertheless, we were able to make these biophysical measurements for the first time using stopped-flow fluorometry, where Ru360-inhibitable mitochondrial $\mathrm{Ca}^{2+}$ influx was quantified with millisecond resolution (Extended Data Fig. 6). Fluo-4 or fluo-4FF was used to measure extramitochondrial (i.e., cytosolic) $\left[\mathrm{Ca}^{2+}\right]_{\mathrm{i}}$, while $\left[\mathrm{Ca}^{2+}\right]_{\mathrm{m}}$ and $\Delta \Psi_{\mathrm{m}}$ were measured with fura-2 and TMRM, respectively; all measurements were performed under identical conditions (see Methods). Fig. 3a shows MCU-mediated $\mathrm{Ca}^{2+}$ influx as a function of $\left[\mathrm{Ca}^{2+}\right]_{\mathrm{i}}$ while Fig. $3 \mathrm{~b}$ shows the relative MCU conductance as a function of $\left[\mathrm{Ca}^{2+}\right]_{\mathrm{i}}$ (see Methods). These measurements are used to obtain the number of open MCU channels as a function of $\left[\mathrm{Ca}^{2+}\right]_{\mathrm{i}}$ (For more details see Supplemental Discussion section 2.4) Our data provide an unambiguous result - the number of open MCU channels remains essentially unchanged over the physiological range of $\left[\mathrm{Ca}^{2+}\right]_{\mathrm{i}}$ in cardiac mitochondria, as shown in Fig. 3c. Furthermore, our data show a surprisingly simple result: As the availability of the conducting ion increases so does its flux, and as $\Delta \Psi_{\mathrm{m}}$ becomes less negative, MCUmediated $\mathrm{Ca}^{2+}$ flux decreases, following the electrochemical driving force for $\mathrm{Ca}^{2+}$ entry into the mitochondrial matrix (see Fig. 3d). The result is surprising because other investigators have reported that the MCU has a $\left[\mathrm{Ca}^{2+}\right]_{\mathrm{i}}$ "threshold" 23,24 of $\sim 1 \mu \mathrm{M}$ for conducting $\mathrm{Ca}^{2+}$, below which no $\mathrm{Ca}^{2+}$ flux is seen. In contrast, we see no threshold, a finding which suggests that a threshold may not be a common feature of all tissues 
(Supplemental Discussion section 2.5). Furthermore, the $\left[\mathrm{Ca}^{2+}\right]_{i}$-gating functions of the $\mathrm{MCU}^{23,24}$ that regulate the number of open MCU channels are not observed by us in cardiac mitochondria under the conditions of these experiments. The putative purpose of the gating/ threshold combination is to limit excessive mitochondrial $\mathrm{Ca}^{2+}$ loading $^{23,24}$. However, our quantitative measurements suggest that this can be achieved by the low number of $\mathrm{MCU}$ channels in heart. Furthermore, the behavior of cardiac myocyte MCUs shown here suggests that $\left[\mathrm{Ca}^{2+}\right]_{\mathrm{m}}$ should track $\left[\mathrm{Ca}^{2+}\right]_{\mathrm{i}}$ in heart without excessive weight being given to elevated $\left[\mathrm{Ca}^{2+}\right]_{\mathrm{i}}$ transients.

Part two of our examination of the movement of cytosolic $\mathrm{Ca}^{2+}$ into the mitochondrial matrix focuses on simultaneous measurements of $\left[\mathrm{Ca}^{2+}\right]_{\mathrm{i}}$ and $\left[\mathrm{Ca}^{2+}\right]_{\mathrm{m}}$ under physiological conditions in patch-clamped ventricular myocytes. The physiological context of cytosolic and mitochondrial $\mathrm{Ca}^{2+}$ is shown in Fig. 3e-j in myocytes patch-clamped and stimulated by 100-ms depolarizations at $0.5 \mathrm{~Hz} .\left[\mathrm{Ca}^{2+}\right]_{\mathrm{m}}$ was measured with a mitochondrially-targeted fluorescent $\mathrm{Ca}^{2+}$ sensor, MityCam, (characterized in Extended Data Fig. 7), while Rhod-2 salt loaded into the cytosol via the patch pipette reported $\left[\mathrm{Ca}^{2+}\right]_{\mathrm{i}}$. The calibrated confocal fluorescence images and signals are shown in Fig. 3e-g. These data show that in the quiescent state, $\left[\mathrm{Ca}^{2+}\right]_{\mathrm{i}}$ and $\left[\mathrm{Ca}^{2+}\right]_{\mathrm{m}}$ are stable and $\left[\mathrm{Ca}^{2+}\right]_{\mathrm{m}}$ is $50-100 \mathrm{nM}$ higher then $\left[\mathrm{Ca}^{2+}\right]_{\mathrm{i}}$ (Fig. 3g-h). Every depolarization-triggered heartbeat evokes a $\left[\mathrm{Ca}^{2+}\right]_{\mathrm{i}}$ transient (Fig. $3 \mathrm{~g}$ and i). With repeated depolarizations, the $\left[\mathrm{Ca}^{2+}\right]_{\mathrm{i}}$ transient peaks become larger (as sarcoplasmic reticulum $\mathrm{Ca}^{2+}$ content increases with stimulation), while the diastolic $\left[\mathrm{Ca}^{2+}\right]_{\mathrm{i}}$ and $\left[\mathrm{Ca}^{2+}\right]_{\mathrm{m}}$ both rise slowly (Fig. $3 \mathrm{~g}, \mathrm{j}$ ). These findings demonstrate that rhythmic elevations of $\left[\mathrm{Ca}^{2+}\right]_{\mathrm{i}}$ do not cause synchronized large transients of $\left[\mathrm{Ca}^{2+}\right]_{\mathrm{m}}$ (Fig. 3i-j). Instead, a series of cytosolic $\mathrm{Ca}^{2+}$ transients causes a gradual beat-dependent elevation of $\left[\mathrm{Ca}^{2+}\right]_{\mathrm{m}}$. Thus, in a physiological context, a single heartbeat cannot materially change $\left[\mathrm{Ca}^{2+}\right]_{\mathrm{m}}$. Rather, a series of heartbeats and their pattern control $\left[\mathrm{Ca}^{2+}\right]_{\mathrm{m}}$ and ATP production.

The clear role of $\Delta \Psi_{\mathrm{m}}$ in regulating ATP production, as shown in Figs. 1-2, is examined quantitatively in Fig. 4. Isolated mitochondria were used in these experiments without highenergy substrate, and were depleted of $\left[\mathrm{Ca}^{2+}\right]_{\mathrm{m}}$ for the initial experiments to minimize the $\left[\mathrm{Ca}^{2+}\right]_{\mathrm{m}}$-dependent contributions. $\Delta \Psi_{\mathrm{m}}$ was controlled independently using valinomycin (a $\mathrm{K}^{+}$ionophore ${ }^{25}$ ) in combination with the $\mathrm{K}^{+}$gradient across the inner mitochondrial membrane; $\Delta \Psi_{\mathrm{m}}$ was measured and calibrated with TMRM. With all other factors held constant, ATP production was measured as a function of $\Delta \Psi_{\mathrm{m}}$ (see Methods). The resulting findings were unexpected. The curve is concave-upward and shows ATP production accelerating as $\Delta \Psi_{\mathrm{m}}$ is increasingly hyperpolarized. To examine further the role of $\left[\mathrm{Ca}^{2+}\right]_{\mathrm{m}}$, the experiment was repeated at high $\left[\mathrm{Ca}^{2+}\right]_{\mathrm{m}}$ and in the presence of high-energy substrate with all other conditions held constant. Fig. 4a shows that the relationship was virtually identical in high and low $\left[\mathrm{Ca}^{2+}\right]_{\mathrm{m}}$ - confirming our earlier findings that $\left[\mathrm{Ca}^{2+}\right]_{\mathrm{m}}$ does not directly regulate the ATP synthase (Fig. 1k-1).

The IMM voltage-dependence of ATP production by ATP synthase (Complex V) in cardiac mitochondria reveals how protons in the intermembrane space use $\Delta \Psi_{\mathrm{m}}$ to power the synthase. Up to now, the known voltage dependence of bacterial ATP synthase has been used as the model system for predicting the behavior of the mammalian ATP synthase ${ }^{25-28}$. The bacterial ATP synthase produces 0 ATP at $0 \mathrm{mV}$, and ATP production rises sigmoidally, 
saturating at $-120 \mathrm{mV}$, with half-saturation at $-70 \mathrm{mV}^{25-28}$. Our data in Fig. $4 \mathrm{a}$ is the first report of the voltage-dependence of the mammalian ATP synthase. The shape of the curve and its quantitative characteristics should provide clues into the inner workings of the mammalian ATP synthase. The shape of the curve is a surprise - it is concave-upwards over the range of $\Delta \Psi_{\mathrm{m}}$ examined and does not suggest saturation. Additionally, in sharp contrast with the bacterial ATP synthase, which reaches $37 \%$ of its maximal rate at -65 $\mathrm{mV}^{25}$, the mammalian enzyme produces essentially no ATP until an apparent "threshold" voltage of $-65 \mathrm{mV}$ is reached. Thermodynamically, the $-65 \mathrm{mV}$ threshold suggests that when $\Delta \Psi_{\mathrm{m}}$ is more positive than about $-65 \mathrm{mV}$, there is insufficient energy when protons are bound to the synthase to enable ATP to be synthesized. Furthermore, Fig. 4a also shows the increase in ATP production from -70 to $-120 \mathrm{mV}$. Over this voltage range, the rates of ATP production are consistent with the need for 3 protons transported across the IMM by ATP synthase for every ATP molecule synthesized from ADP (red line in Fig. 4a). This follows a "standard model" of harnessing the energy of protons moving through the voltage field across the inner membrane to produce $\mathrm{ATP}^{28}$. On the other hand, at potentials more negative than $-120 \mathrm{mV}$, the measured rates of ATP production exceed the red line. The slope of the data over the range -130 to -170 rises to approximately four times that predicted by the red line. This finding is thus completely unexpected and has not been seen before. Mechanistically, we do not know why ATP production increases so quickly with $\Delta \Psi_{\mathrm{m}}$. We propose that the number of protons that move across the voltage field of the IMM via a single ATP synthase cycle can increase as $\Delta \Psi_{\mathrm{m}}$ hyperpolarizes negative to $-120 \mathrm{mV}$. In which case, this high rate of ATP production at more hyperpolarized IMM voltages is due to an increase in the stoichiometry of the ATP synthase (more protons moved per ATP produced), which we call "adaptive stoichiometry". A second possibility is a nonlinear voltage-dependent increase in the "rotation" of the C-ring of ATP synthase with unchanged stoichiometry, which may be termed "adaptive kinetics". While one or more of these hypothesized voltage-sensitive mechanisms may apply, we do not yet have experimental techniques that enable us to determine which. Nevertheless, it is clear from the data that the voltage-dependence shown in Fig. 4a differs radically from the measured voltagedependence of the bacterial ATP synthase. This feature may represent an improvement of metabolic adaptation in mammalian systems. It enables a higher rate of ATP production when it is needed and when the energy is available in the form of $\Delta \Psi_{\mathrm{m}}$. Additional discussion of several likely important features of the mammalian ATP synthase is presented in the Supplemental Discussion section 2.6 and in Supplemental Information section 1.1.

Our examination of ATP production and its regulation in the heart is diagrammed in Fig. 4b. We found that mitochondrial production of ATP is controlled by $\Delta \Psi_{\mathrm{m}}$, which is sensitive to [ADP] and to $\left[\mathrm{Ca}^{2+}\right]_{\mathrm{m}}$. We propose that the $\Delta \Psi_{\mathrm{m}}$ dependence of ATP production that we show here in cardiac mitochondria is a general feature of mammalian mitochondria. In support of this view, we carried out similar experiments with skeletal muscle mitochondria, and found the same $\Delta \Psi_{\mathrm{m}}$ dependence of ATP production (see Extended Data Fig. 8).

Nevertheless, these and other and tissue-specific mitochondrial features need further study. For example, in virtually all tissues the basal and dynamic ATP consumption rates are likely to be different ${ }^{2,3}$. Furthermore, the dynamic $\left[\mathrm{Ca}^{2+}\right]_{\mathrm{i}}$ signals are also generally cell-type- and tissue-specific ${ }^{29,30}$. Moreover, we and others show that MCU properties vary significantly in 
different eukaryotic species ${ }^{19}$ and tissues ${ }^{1}$ (see Extended Data Fig. 8 that compares our measurements of cardiac MCU to skeletal muscle MCU). Taken together, our findings and the developed quantitative tools lay the foundation to reshape our thinking and approach to energy utilization under physiological and pathophysiological conditions and in mitochondrial diseases.

\section{METHODS}

\section{Mitochondria isolation.}

6-10-week-old Sprague-Dawley male rats (250-300 gr, from ENVIGO, USA, stain code \# 002) were anesthetized using Isofluorane (10 minutes) and administered heparin IP (720 U per $\mathrm{Kg}, 5$ minutes). A thoracotomy and fast excision of the heart was performed, with removal of the atria. The ventricles were minced in ice cold isolation buffer (IB) containing (in $\mathrm{mM}$ ): $\mathrm{KCl} 100$, MOPS 50, $\mathrm{MgSO}_{4}$ 5, EGTA 2, NaPyruvate 10, $\mathrm{K}_{2} \mathrm{HPO}_{4} 10$. The minced tissue was washed repeatedly with IB until clear of blood. The remainder of the preparation was conducted in a cold room $\left(4^{\circ} \mathrm{C}\right) .20 \mathrm{~mL}$ of IB containing tissue was transferred to a Potter-Elvehjem grinder and homogenized at high speed for 2 seconds followed by 4 repetitive homogenizations with a 1-micron clearance pestle on low. The homogenate was centrifuged for $8 \mathrm{~min}$ at $600 \mathrm{~g}$ after which the supernatant was transferred to a new centrifuge tube. The pellet was resuspended with $10 \mathrm{~mL}$ IB and centrifuged for $8 \mathrm{~min}$ at $600 \mathrm{~g}$. The second supernatant was pooled with the first and centrifuged again for $8 \mathrm{~min}$ at $600 \mathrm{~g}$. The final supernatant was transferred to a clean centrifuge tube and spun at $3200 \mathrm{~g}$ for $8 \mathrm{~min}$. The resulting supernatant was discarded and the pellet is the mitochondria sample. The mitochondria were then resuspended in resuspension buffer base solution (RB) consisting of (in $\mathrm{mM}$ ): $\mathrm{KCl} 100$, MOPS $50, \mathrm{~K}_{2} \mathrm{HPO}_{4} 1$ or 10 . The RB1 was RB supplemented with NaPyruvate (10 mM), EGTA (10 or $40 \mu \mathrm{M})$, and with the acetoxymethyl (AM) ester forms of either a calcium indicator (Rhod-2 AM $(3 \mu \mathrm{M})$ or Fura-2 AM $(5 \mu \mathrm{M})$ ) or the $\mathrm{pH}$ indicator BCECF AM $(10 \mu \mathrm{M})$. Mitochondria were loaded with the respective dye for $30 \mathrm{~min}$ after which they were pelleted at $3200 \mathrm{~g}$ for $8 \mathrm{~min}$. The pellet was then resuspended in RB2 which is RB supplemented with NaPyruvate $(1 \mathrm{mM})$ and depending on the experiment; either EGTA $(40 \mu \mathrm{M})$ or $10 \mu \mathrm{M}$ Fluo-4 was used. Mitochondria in RB2 are pelleted at $3200 \mathrm{~g}$ for 8 min. A third and final resuspension and pelleting was done using RB3 consisting of RB and either EGTA $(40 \mu \mathrm{M})$ or $10 \mu \mathrm{M}$ Fluo- 4 . The concentration of mitochondria in $\mathrm{mg} / \mathrm{mL}$ was quantified by Lowry assay with a typical rat heart yielding $\sim 15 \mathrm{mg}$ mitochondrial protein. Mitochondria isolated from this preparation exhibited typical respirometry outputs (Qubit MitoCell $37{ }^{\circ} \mathrm{C}$ - State 3: $178.4 \pm 10.6 \mathrm{nmol} / \mathrm{mg} / \mathrm{min}$, State $4+$ Oligomycin A: $11.6 \pm 1.02$ $\mathrm{nmol} / \mathrm{mg} / \mathrm{min}$, RCR $12.3 \pm 1.46$, Substrate $1 \mathrm{mM}$ Pyruvate and $0.5 \mathrm{mM}$ Malate) and (Seahorse XFe96 Analyzer $37{ }^{\circ} \mathrm{C}$ - State 3: $110.2 \pm 11.5 \mathrm{nmol} / \mathrm{mg} / \mathrm{min}$, State $4+$ Oligomycin A: $11.6 \pm 2.6 \mathrm{nmol} / \mathrm{mg} / \mathrm{min}, \mathrm{RCR} 9.4 \pm 1.6$, Substrate $10 \mathrm{mM}$ Glutamate and 5 $\mathrm{mM}$ Malate). Skeletal muscle mitochondria were isolated from the gastrocnemius muscle using the protocol described above but with the following modification. The harvested muscle tissue was minced in ice cold isolation buffer (IB) containing $5 \mathrm{mM}$ of EGTA and no pyruvate. Mitochondria isolated from this preparation exhibited typical respirometry outputs (Seahorse XFe96 Analyzer $37{ }^{\circ} \mathrm{C}$ - State 3: $87 \pm 7.4 \mathrm{nmol} / \mathrm{mg} / \mathrm{min}$, State $4+$ Oligomycin A: $9.2 \pm 2.9 \mathrm{nmol} / \mathrm{mg} / \mathrm{min}, \mathrm{RCR} 9.5 \pm 1.2$, Substrate $10 \mathrm{mM}$ Glutamate and $5 \mathrm{mM}$ Malate). All 
procedures and protocols involving animal use were approved by the Institutional Animal Care and Use Committee of the University of Maryland School of Medicine.

\section{Isolation of adult cardiomyocyte.}

Isolated ventricular myocytes were obtained from adult male Sprague-Dawley rats (250-300 g, from ENVIGO, USA, stain code \# 002). Rats were deeply anesthetized by inhalation of vaporized isoflurane and heparinized $(720 \mathrm{U}$ per $\mathrm{Kg}$ ). Ten minutes after heparin was injected, the heart was rapidly excised and rinsed with ice cold $500 \mu \mathrm{M}$ EGTA isolation buffer containing $130 \mathrm{mM} \mathrm{NaCl}, 5.4 \mathrm{mM} \mathrm{KCl}, 0.5 \mathrm{mM} \mathrm{MgCl} 2,0.33 \mathrm{mM} \mathrm{NaH}_{2} \mathrm{PO}_{4}, 10 \mathrm{mM}$ D-glucose, $10 \mathrm{mM}$ Taurine, $25 \mathrm{mM}$ HEPES, and $0.01 \mathrm{unit} / \mathrm{mL}$ insulin (pH 7.4) (adjusted with $\mathrm{NaOH}$ ). The aorta was quickly cannulated for Langendorff perfusion. The heart coronary arteries were perfused at $37^{\circ} \mathrm{C}$ for 2 min with EGTA isolation buffer and then perfused for $7 \mathrm{~min}$ with isolation buffer supplemented with $1 \mathrm{mg} / \mathrm{mL}$ collagenase (type II; Worthington Bio- chemical, USA), $0.06 \mathrm{mg} / \mathrm{mL}$ protease (XIV), $0.06 \mathrm{mg} / \mathrm{mL}$ Trypsin, and $0.3 \mathrm{mM} \mathrm{CaCl}_{2}$. The ventricles were cut down, minced, and kept in the same buffer for additional 6 minutes at $36^{\circ} \mathrm{C}$. The myocardium was dispersed to form a cell suspension, which was then filtered through a Nylon mash filter $(300 \mu \mathrm{m})$. The filtrate was spun at $180 \mathrm{~g}$ and the cell containing pellet was resuspended in isolation buffer supplemented with 2 $\mathrm{mg} / \mathrm{mL} \mathrm{BSA} . \mathrm{Ca}^{2+}$ is gradually added at 4 increments of $0.4 \mathrm{mM}$ every 12 minutes. Cells were allowed to pellet by sedimentation, resuspended in NT solution, and were used within 4 hours of isolation. All procedures and protocols involving animal use were approved by the Institutional Animal Care and Use Committee of the University of Maryland School of Medicine.

\section{Measuring the dissociation constants of $\mathrm{Ca}^{2+}$ indicators.}

Fluorescence titration curves with $\mathrm{Ca}^{2+}$ were done to measure the $\left[\mathrm{Ca}^{2+}\right]$ dissociation constants $\left(K_{\mathrm{d}}\right)$ of the indicators used (see Extended Data Fig. 2). The $K_{\mathrm{d}}$ of Fluo-4, Fluo-4FF, and Rhod-2 are measured in the relevant experimental buffers using the method by Eberhard M \& Erne $\mathrm{P}^{31}$ as shown in Extended Data Fig. 2 a-c. The $K_{\mathrm{d}}$ of Fura-2 and Rhod-2 loaded via their acetoxymethyl (AM) form into the matrix of isolated mitochondria was measured using the $\mathrm{Ca}^{2+}$ ionophore Ionomycin to equilibrate the free mitochondrial $\mathrm{Ca}^{2+}\left(\left[\mathrm{Ca}^{2+}\right]_{\mathrm{m}}\right)$ with the free extra mitochondrial $\mathrm{Ca}^{2+}\left(\left[\mathrm{Ca}^{2+}\right]_{\text {extra, free }}\right.$ ), (see Extended Data Fig. 2 d).

\section{Measurements of mitochondrial ATP production \& $\left[\mathrm{Ca}^{2+}\right]_{\mathrm{m}}$.}

Measurements of mitochondrial ATP production rate and $\left[\mathrm{Ca}^{2+}\right]_{\mathrm{m}}$ were carried out using a BMG LABTECH CLARIOstar plate reader. Rhod-2 AM loaded mitochondria ( $0.1 \mathrm{mg}$ per $\mathrm{mL}$ ) are mixed in ATP production assay buffer (AB) consisting of (in $\mathrm{mM}$ ): KGluconate $130, \mathrm{KCl} 5, \mathrm{~K} 2 \mathrm{HPO} 41$ or $10, \mathrm{MgCl}_{2}$ 1, HEPES 10, EGTA 0.04, BSA $0.5 \mathrm{mg} / \mathrm{mL}$, DLuciferin (Sigma) 0.005, Luciferase (Roche) $0.001 \mathrm{mg} / \mathrm{mL}$. A luminescence standard curve was performed daily over a range of $100 \mathrm{nM}$ to $1 \mathrm{mM}$ ATP with Oligomycin A (15 $\mu \mathrm{M})$ treated mitochondria, see Extended Data Fig. 1 a-c. The mitochondria were incubated for 2 minutes prior to the start of the assay with $\mathrm{Ca}^{2+}(0-50 \mu \mathrm{M}$ added) and metabolic substrates. Assays were initiated by injection of $100 \mu \mathrm{L}$ of ADP (50-500 $\mu \mathrm{M})$ and luciferin/luciferase in $\mathrm{AB}$ to bring the final volume to $200 \mu \mathrm{L}$. Luminescence signal is recorded for 20 seconds 
with 1 second integration. In the absence of ADP only 10 nM ATP is present in the system. An automated sequence was used to assess each well first for luminescence then subsequently for fluorescence, see Extended Data Fig. $1 \mathrm{a}-\mathrm{c}$ for representative traces and analysis. ATP production rates are scaled to a liter of cardiomyocyte cytosol $\left(\mu \mathrm{M} \mathrm{s}^{-1}\right.$, scaling is based on 80 gram mitochondrial protein per liter cardiomyocyte cytosol $)^{7}$. $\left[\mathrm{Ca}^{2+}\right]_{\mathrm{m}}$ was measured via Rhod-2 fluorescence (excitation: $554 \pm 4 \mathrm{~nm}$, emission: $607 \pm 24 \mathrm{~nm}$ ) with a $\mathrm{F}_{\mathrm{Max}}$ and $\mathrm{F}_{\mathrm{Min}}$ obtained daily ( $\mathrm{F}_{\mathrm{Min}}$ at $2 \mathrm{mM}$ EGTA, $\mathrm{F}_{\mathrm{Max}}$ at $2 \mathrm{mM} \mathrm{Ca}^{2+}$ ). The quantitative $\left[\mathrm{Ca}^{2+}\right]_{\mathrm{m}}$ values were obtained according to the following equation (1):

$$
\left[\mathrm{Ca}^{2+}\right]_{\mathrm{m}}=K_{\mathrm{d}, \mathrm{R} 2 \mathrm{~m}}\left[\mathrm{~F}_{\text {Rhod }}-\mathrm{F}_{\text {Rhod,Min }}\right] /\left[\mathrm{F}_{\text {Rhod,Max }}-\mathrm{F}_{\text {Rhod }}\right] \text {. }
$$

Were $K_{\mathrm{d}, \mathrm{R} 2 \mathrm{~m}}=1.74 \mu \mathrm{M}$, obtained as described above, also see Extended Data Fig. $2 \mathrm{~d}$. Critical for each isolated mitochondria test was the purification of ADP stocks. Briefly; Na ADP (Sigma) or K ADP (Sigma) were dissolved in a reaction buffer containing (in $\mathrm{mM}$ ): $\mathrm{Na}$ ADP or K ADP 500, Glucose 10, Tris 50, $\mathrm{MgCl}_{2} 5$, and $50 \mathrm{U} / \mathrm{mL}$ Hexokinase, $\mathrm{pH}$ 7.4. The reaction was given 1 hour at $30{ }^{\circ} \mathrm{C}$ after which the solution was filtered using filtered centrifugal tubes with a molecular cut-off of 3,000 Dalton (Amicon Ultra, Milipore, Ireland). The concentration of the ADP stock was re-assessed by measuring absorbance at $260 \mathrm{~nm}$ and using an extinction coefficient of $15,400 \mathrm{M}^{-1} \mathrm{~cm}^{-1}$ according to the Beer-Lambert law.

\section{Measurements of $\Delta \Psi_{\mathrm{m}} \&\left[\mathrm{Ca}^{2+}\right]_{\mathrm{m}}$.}

Measurements of $\Delta \Psi_{\mathrm{m}}$ and $\left[\mathrm{Ca}^{2+}\right]_{\mathrm{m}}$ were carried out using either a BMG LABTECH CLARIOstar plate reader or Stopped-Flow instrument (SF-300×, KinTek, USA). In these experiments, Fura- 2 AM loaded mitochondria $(0.25 \mathrm{mg}$ per $\mathrm{mL})$ were mixed in ATP production assay buffer $(\mathrm{AB})$ without BSA and supplemented with $0.5 \mu \mathrm{M}$ TMRM $(2 \mu \mathrm{M}$ TMRM per $1 \mathrm{mg}$ per $\mathrm{mL}$ mitochondrial protein). The CLARIOstar was used for experiments testing $\Delta \Psi_{\mathrm{m}}$ depolarization over a range of both $\mathrm{Ca}^{2+}(0-50 \mu \mathrm{M}$ added $)$ and ADP $(0-500$ $\mu \mathrm{M})$ using Pyruvate $(1 \mathrm{mM})$ and Malate $(0.5 \mathrm{mM})$ for substrate. After 2 minutes of incubation with substrate and $\mathrm{Ca}^{2+}$, assays were initiated by injection of $100 \mu \mathrm{L}$ of ADP to bring the final volume to $200 \mu \mathrm{L}$. TMRM (excitation: $546 \pm 4 \mathrm{nM}$ and $573 \pm 5 \mathrm{~nm}$, emission: $619 \pm 15 \mathrm{~nm}$ ) and Fura-2 (excitation: $335 \pm 6 \mathrm{nM}$ and $380 \pm 6 \mathrm{~nm}$, emission: $490 \pm 15 \mathrm{~nm}$ ) fluorescence were measured within the same well for 20 seconds. Stopped flow measurements were done using the same buffers and 3 distinct protocols. Protocol 1 mitochondria were pre-incubated for 2 minutes with $\mathrm{Ca}^{2+}$ then stimulated with $500 \mu \mathrm{M}$ ADP. Protocol 2 - mitochondria with $\left[\mathrm{Ca}^{2+}\right]_{\mathrm{m}}$ of less than $50 \mathrm{nM}$ were simultaneously stimulated with $500 \mu \mathrm{M}$ ADP and high $\mathrm{Ca}^{2+}$. Protocol 3 - mitochondria with $\left[\mathrm{Ca}^{2+}\right]_{\mathrm{m}}$ of less than $50 \mathrm{nM}$ were pre-mixed with $500 \mu \mathrm{M}$ ADP, followed by mixing with high $\mathrm{Ca}^{2+}$ while keeping constant $500 \mu \mathrm{M}$ ADP. All 3 protocols were executed for 20 seconds. TMRM (excited with $546 \mathrm{~nm}$ and $573 \mathrm{~nm}, 593-643 \mathrm{~nm}$ emission) and Fura-2 (excited with $340 \mathrm{~nm}$ and $380 \mathrm{~nm}, 491-501 \mathrm{~nm}$ emission) signals were measured in parallel for each injection set. The $\left[\mathrm{Ca}^{2+}\right]_{\mathrm{m}}$ was obtained according to the following equation (2):

$$
\left[\mathrm{Ca}^{2+}\right]_{\mathrm{m}}=K_{\mathrm{d}, \mathrm{F} 2 \mathrm{~m}} \beta\left[\mathrm{R}_{\mathrm{F} 2}-\mathrm{F}_{\mathrm{F} 2, \mathrm{Min}}\right] /\left[\mathrm{F}_{\mathrm{F} 2, \mathrm{Max}}-\mathrm{F}_{\mathrm{F} 2}\right] .
$$


where, $K_{\mathrm{d}, \mathrm{F} 2 \mathrm{~m}}=0.26 \mu \mathrm{M}$, was obtained as described above (see Extended Data Fig. $2 \mathrm{~d}$ ). The $\beta\left(F_{380, \min } / F_{380, \max }\right)$ was measured daily (typically $\left.2.5-2.8\right)$. Fura- $2 \mathrm{R}_{\text {Max }}(340 \mathrm{~nm} / 380$ $\mathrm{nm}$ ) and $\mathrm{R}_{\text {Min }}$ were obtained daily for both Stopped-Flow and plate-reader assays. TMRM signal was calibrated using the ratiometric Scaduto \& Grotyohann method ${ }^{32}$ as shown in Extended Data Fig. 1 e-h. The protonophore 2,4-dinitrophenol (DNP) was used to depolarize $\Delta \Psi_{\mathrm{m}}$ to different levels to generate the standard curves of TMRM calibration as shown in Extended Data Fig. $1 \mathrm{e}-\mathrm{h}$.

\section{Measurements of $\mathrm{pHm} \&\left[\mathrm{Ca}^{2+}\right]_{\mathrm{m}}$.}

Measurements of $\mathrm{pHm}$ and $\left[\mathrm{Ca}^{2+}\right]_{\mathrm{m}}$ were carried out using a BMG LABTECH CLARIOstar plate reader. In these experiments, Rhod-2 AM and BCECF AM co-loaded mitochondria ( $0.25 \mathrm{mg}$ per $\mathrm{mL}$ ) were mixed in $\mathrm{AB}$. The mitochondria were incubated for 2 minutes prior to the start of the assay with $\mathrm{Ca}^{2+}(0-50 \mu \mathrm{M}$ added $)$ and Pyruvate $(1 \mathrm{mM})$ and Malate $(0.5$ $\mathrm{mM})$. Assays were initiated by injection of $100 \mu \mathrm{L}$ of $\mathrm{ADP}(0$ or $500 \mu \mathrm{M})$ in $\mathrm{AB}$ to bring the final volume to $200 \mu \mathrm{L}$. BCECF (excitation: $430 \pm 5 \mathrm{~nm}$ and $500 \pm 5 \mathrm{~nm}$, emission: $540 \pm 10$ $\mathrm{nm}$ ) and Rhod-2 signals were recorded for 20 seconds. $\mathrm{F}_{\mathrm{Max}}$ and $\mathrm{F}_{\mathrm{Min}}$ was obtained daily for each indicator (BCECF: $\mathrm{F}_{\mathrm{Min}} \mathrm{pH}=4.5, \mathrm{~F}_{\mathrm{Max}} \mathrm{pH}=9$ ). The $\mathrm{pKa}$ of BCECF-AM in isolated mitochondria was determined to be 7.26 using mitochondria treated with $1 \mu \mathrm{M} \mathrm{FCCP}$ and allowed to equilibrate with the extra-mitochondrial $\mathrm{pH}$ using an array of different $\mathrm{pH}$ buffers (see Extended Data Fig. $1 \mathrm{i}-\mathrm{j}$ for excitation and emission spectra). Acid-loading experiments using iso-osmotic solutions of $\mathrm{Na}$ Acetate are done to ensure BCECF-AM remained within the mitochondria, see Extended Data Fig. 1 k.

\section{Measurements of mitochondrial $\mathrm{Ca}^{2+}$ influx.}

Measurements of mitochondrial $\mathrm{Ca}^{2+}$ influx were carried-out using Stopped-Flow instrument (SF-300×, KinTek, USA). For physiological extra-mitochondrial free $\mathrm{Ca}^{2+}$ $\left(\left[\mathrm{Ca}^{2+}\right]_{\text {extra,free }}<4 \mu \mathrm{M}\right)$ experiments, Fura-2 AM loaded mitochondria $(4 \mathrm{mg}$ per $\mathrm{ml})$ in uptake assay buffer $(\mathrm{uAB})$ were rapidly mixed by the Stopped-Flow with equal volume of uAB supplemented with $\mathrm{Ca}^{2+}$. Thereby, a step-wise increase of $\left[\mathrm{Ca}^{2+}\right]_{\text {extra,free }}$ occurs within $1 \mathrm{~ms}$ from about $50 \mathrm{nM}$ to as high as $3 \mu \mathrm{M}$. The $\mathrm{uAB}$ consisted of (in $\mathrm{mM}$ ): $\mathrm{KCl} 130$ (Trace Select, Sigma Aldrich), HEPES 20, Pyruvic acid 10, Malic acid 5, $\mathrm{K}_{2} \mathrm{HPO}_{4} 1, \mathrm{MgCl}_{2} 1$, and Fluo-4 0.003 (Pentapotassium Salt, Thermo Fisher), pH 7.2 with $\mathrm{KOH} . \mathrm{Na}^{+}$was not added to the $\mathrm{uAB}$ or to the isolation buffer in which the mitochondria were suspended and kept (i.e., RB). The uAB is made with analytical grade deionized water (OmniSolv® LC-MS, Sigma Aldrich) and contained less than $50 \mathrm{nM}$ of residual $\left[\mathrm{Ca}^{2+}\right]$. Under these experimental conditions, Fluo-4 is the single significant buffer of extra-mitochondrial $\mathrm{Ca}^{2+}$ (See Extended Data Figs. 2 and 6). Therefore, Fluo-4 fluorescence can be used for measurements of $\left[\mathrm{Ca}^{2+}\right]_{\text {extra,free }}$ and the total extra-mitochondrial $\mathrm{Ca}^{2+}\left(\left[\mathrm{Ca}^{2+}\right]_{\text {extra,Total }}\right)$ both in units of $\mu \mathrm{M}$ using the following equation (3):

$$
\left[\mathrm{Ca}^{2+}\right]_{\text {extra, free }}=K_{\mathrm{d}, \text { Fluo4 }}\left[\mathrm{F}_{\text {Fluo-4 }}-\mathrm{F}_{\text {Fluo-4, Min }}\right] /\left[\mathrm{F}_{\text {Fluo-4, Max }}-\mathrm{F}_{\text {Fluo-4 }}\right]
$$

where $\mathrm{F}_{\text {Fluo-4,Min }}$ is the fluorescence intensity of Fluo-4 in the absence of calcium (measured with $2 \mathrm{mM}$ of EGTA in the uAB), $\mathrm{F}_{\text {Fluo-4,Max }}$ is the fluorescence of the calcium saturated Fluo-4 (measured with $2 \mathrm{mM}\left[\mathrm{Ca}^{2+}\right]$ in the $\mathrm{uAB}$ ). The $\mathrm{Ca}^{2+}$ dissociation constant of Fluo-4 
( $K_{\mathrm{d}, \text { Fluo4 }}$ ) is taken as $0.72 \mu \mathrm{M}$ (See Extended Data Fig. 2). Fluo-4 binds to $\mathrm{Ca}^{2+}$ with 1-to-1 stoichiometry allowing the calculation of $\left[\right.$ Fluo- $\left.4: \mathrm{Ca}^{2+}\right]$ in units of $\mu \mathrm{M}$ using the following equation (4):

$$
\text { [Fluo-4: } \left.\mathrm{Ca}^{2+}\right]=\left[\mathrm{F}_{\text {Fluo-4 }}-\mathrm{F}_{\text {Fluo-4, Min }}\right] /\left[\mathrm{F}_{\text {Fluo-4, Max }}-\mathrm{F}_{\text {Fluo-4, Min }}\right]
$$

The sum of $\left[\mathrm{Ca}^{2+}\right]_{\mathrm{extra} \text {,free }}$ and the concentration of $\mathrm{Ca}^{2+}$ bound to Fluo-4 ([Fluo-4:Ca $\left.{ }^{2+}\right]$ ) yield the $\left[\mathrm{Ca}^{2+}\right]_{\text {extra,Total }}$ using the following equation (5):

$$
\left[\mathrm{Ca}^{2+}\right]_{\text {extra,Total }}=\left[\mathrm{Ca}^{2+}\right]_{\text {extra,free }}+\left[\text { Fluo- } 4: \mathrm{Ca}^{2+}\right]
$$

The first derivative of the time-dependent measured $\left[\mathrm{Ca}^{2+}\right]_{\text {extra,Total }}$ is the mitochondrial $\mathrm{Ca}^{2+}$ influx. In these experiments, mitochondrial $\mathrm{Ca}^{2+}$ influx is completely blocked by $1 \mu \mathrm{M}$ of Ru360, and is therefore identified as MCU flux $\left(\mathrm{J}_{\mathrm{mcu}}\right)$ and scaled to a liter of cardiomyocyte cytosol $\left(\mu \mathrm{M} \mathrm{s}^{-1}\right.$ scaling is based on 80 gram mitochondrial protein per liter cardiomyocyte cytosol) ${ }^{7}$. To measure $\left[\mathrm{Ca}^{2+}\right]_{\mathrm{m}}$ mitochondria were loaded with Fura-2 AM (calibration described above) and loaded with TMRM to measure $\Delta \Psi_{\mathrm{m}}$ in $\mathrm{mV}$ (calibration described above). The total MCU Ca ${ }^{2+}$ conductance $\left(G_{m c u}\right)$ was obtained from the measurements of $\mathrm{J}_{\mathrm{mcu}},\left[\mathrm{Ca}^{2+}\right]_{\mathrm{i}},\left[\mathrm{Ca}^{2+}\right]_{\mathrm{m}}$, and $\Delta \Psi_{\mathrm{m}}$ according to the following equation (6):

$$
\mathrm{J}_{\mathrm{mcu}}=\mathrm{I}_{m c u} /\left(2 \mathrm{FV}_{\mathrm{i}}\right), \mathrm{I}_{m c u}=G_{m c u}\left(\Delta \Psi_{\mathrm{m}}-\mathrm{E}_{\mathrm{Ca}^{2}}{ }^{+}\right)
$$

where $\mathrm{V}_{\mathrm{i}}$ is the myoplasm volume $18 \mathrm{pL}$ and $\mathrm{E}_{\mathrm{Ca}^{2+}}$ is the Nernst reversal potential for $\mathrm{Ca}^{2+}$. The number of open $\mathrm{MCU}$ channels per mitochondrion are obtained from the measurements of $\mathrm{J}_{\mathrm{mcu}},\left[\mathrm{Ca}^{2+}\right]_{\mathrm{i}},\left[\mathrm{Ca}^{2+}\right]_{\mathrm{m}}$, and $\Delta \Psi_{\mathrm{m}}$ according to the following equation (7):

$$
\text { Number of open MCUs }=G_{m c u} / g_{\mathrm{mcu}}
$$

where $\mathrm{g}_{\mathrm{mcu}}$ is single channel MCU conductance $\left(\mathrm{g}_{\mathrm{mcu}, \max }=3.25 \mathrm{pS}, K_{\mathrm{m} . \mathrm{mcu}}=19 \mathrm{mM}\right.$ $\left.\left[\mathrm{Ca}^{2+}\right]_{\mathrm{i}}^{7,18,33}\right)$. For experiments where $\left[\mathrm{Ca}^{2+}\right]_{\text {extra,free }}$ is stepped to values between $4-12 \mu \mathrm{M}$, Fluo-4FF $\left(K_{\mathrm{d}, \mathrm{Fluo} 4 \mathrm{FF}}=21.6 \mu \mathrm{M}\right.$, see Extended Data Fig. 2$)$ was used instead of Fluo-4. These experiments were carried-out with a lower concentration of mitochondria for 5 seconds ( $1 \mathrm{mg}$ per ml post mix) with uAB supplemented with $10 \mu \mathrm{M}$ of EGTA. Since EGTA is saturated with $\mathrm{Ca}^{2+}$ when the $\left[\mathrm{Ca}^{2+}\right]_{\text {extra,free }}$ is greater than $3.5 \mu \mathrm{M}$, these experiments were analyzed in the same manner as the experiments with Fluo-4. Fluo-4 and Fluo-4FF were excited at $485 \mathrm{~nm}, 520-542$ emission. Fura- 2 were excited with $340 \mathrm{nM}$ and $380 \mathrm{~nm}$, 491-501 emission. TMRM was excited at $546 \mathrm{nM}$ and $573 \mathrm{~nm}, 593-643$ emission.

\section{Valinomycin $\Delta \Psi_{\mathrm{m}}$ clamp: mitochondrial ATP production \& mitochondrial $\mathrm{Ca}^{2+}$ influx.}

$\Delta \Psi_{\mathrm{m}}$ clamp experiments were carried out using a BMG LABTECH CLARIOstar plate reader. The $\Delta \Psi_{\mathrm{m}}$ clamp was achieved using valinomycin and a $\mathrm{K}^{+}$gradient established between the mitochondria and the extra-mitochondrial solution. The extra-mitochondrial solution is varied from 0 to $70 \mathrm{mM}$ while the mitochondrial matrix contained the same amount of $\mathrm{K}^{+}$at the beginning of each experiment (loaded to a steady-state level of $\mathrm{K}^{+}$the 
during the $\sim 3$ hour isolation procedure in buffers with $100 \mathrm{mM} \mathrm{K}^{+}$). Two primary buffers were used (in mM): 1) $\mathrm{K}^{+}$Free Buffer - Gluconic Acid 130, Tetramethyl Ammonium Hydroxide 130, $\mathrm{NaH}_{2} \mathrm{PO}_{4} 1, \mathrm{MgCl}_{2}$ 1, HEPES 20, and EGTA 0.04, pH 7.2 with $\mathrm{HCl}$. 2) High $\mathrm{K}^{+}$Buffer - KGluconate 130, $\mathrm{KCl} 5, \mathrm{NaH}_{2} \mathrm{PO}_{4} 1, \mathrm{MgCl} 2$ 1, HEPES 20, and EGTA $0.04 \mathrm{pH}, 7.2$ with KOH. Buffers were supplemented with D-Luciferin (Sigma) 0.005, Luciferase (Roche) $0.001 \mathrm{mg} / \mathrm{mL}$ and $2 \mu \mathrm{M}$ TMRM per $1 \mathrm{mg}$ per $\mathrm{mL}$ mitochondrial protein. Valinomycin was used at a final concentration of $1 \mu \mathrm{M}$. For ATP production experiments, a $0.5 \mu \mathrm{L}$ of $100 \mathrm{mg}$ per $\mathrm{mL}$ mitochondria stock was added to a well and re-suspended with a desired amount of high $\mathrm{K}^{+}$buffer. Three groups were assessed: 1) no substrate and $\left[\mathrm{Ca}^{2+}\right]_{\mathrm{m}}$ $<200 \mathrm{nM}$, 2) $1 \mathrm{mM}$ pyruvate and $0.5 \mathrm{mM}$ malate with $\left[\mathrm{Ca}^{2+}\right]_{\mathrm{m}}<200 \mathrm{nM}$, and 3) $1 \mathrm{mM}$ pyruvate and $0.5 \mathrm{mM}$ malate with $\left[\mathrm{Ca}^{2+}\right]_{\mathrm{m}}>2 \mu \mathrm{M}$. One injector was then used to add a desired amount of $\mathrm{K}^{+}$free buffer bringing the volume of the well to $190 \mu \mathrm{L}$. An initial TMRM and Fura 2 measurement was recorded for $30 \mathrm{~s}$ allowing the mitochondria to establish a steady-state $\Delta \Psi_{\mathrm{m}}$. ATP production was initiated with an injection of $10 \mathrm{uL} 10$ $\mathrm{mM}$ ADP (final [ADP] $500 \mu \mathrm{M}$ ) and 2 seconds mixing. Luminescence was measured for 15 seconds with 1 second integration (calibrated daily). A final TMRM measurement was recorded for 15 seconds to ensure no change in $\Delta \Psi_{\mathrm{m}}$ over the course of the experiment. For mitochondrial $\mathrm{Ca}^{2+}$ influx vs $\Delta \Psi$ m the assay was conducted (in the absence of $\mathrm{NaH}_{2} \mathrm{PO}_{4}$ and only $10 \mu \mathrm{M}$ EGTA) with parallel measurement of TMRM and $\mathrm{Ca}^{2+}$ influx using Fluo-4FF (as described above). $\mathrm{Ca}^{2+}$ influx experiments were conducted at a $\left[\mathrm{Ca}^{2+}\right]_{\text {extra,free }}$ of $15-17 \mu \mathrm{M}$.

\section{Encapsulation of cardiomyocytes in a resistive hydrogel and measurements of $\Delta \Psi_{\mathrm{m}}$ and sarcomere length.}

The 14\% Poly (vinyl alcohol) (PVA) hydrogel was prepared daily; 14 gr PVA was dissolved in $100 \mathrm{~mL}$ NT solution by stirring at $90{ }^{\circ} \mathrm{C}$, spun down at $200 \mathrm{G}$ to remove air, and kept at $25^{\circ} \mathrm{C}$. Equal volumes of isolated cardiomyocyte suspension and PVA hydrogel were mixed on the glass bottom of a plastic imaging chamber (Lab-Tek ${ }^{\mathrm{TM}}$ Chambered No 1 Coverglass) and supplemented with cell-to-gel linker to a final concentration of $7.5 \%$ linker (i.e., 4armed PEG-boronic acid, see next section for synthesis details and Extended Data Fig. 4). Prior to mixing of cardiomyocytes with the hydrogel, the cells were incubated for 20 minutes in NT solution $\left(36^{\circ} \mathrm{C}\right)$ supplemented with $50 \mathrm{nM}$ TMRM. This NT solution contained Pyruvate $(1 \mathrm{mM})$ and Malate $(0.5 \mathrm{mM})$, or diAM-Succinate (Succinic acid diacetoxymethyl ester, $10 \mu \mathrm{M})$ and rotenone $(5 \mu \mathrm{M})$, or Succinate $(1 \mathrm{mM})$ and rotenone $(5$ $\mu \mathrm{M})$. Incubations and subsequent experiments were done in solutions of the same composition. The hydrogel was given 4 minutes to cross-link after which the plastic imaging chamber was connected to electric stimulation wires and placed inside a microscope stagetop incubator (INU TIZW, TOKAI HIT, Japan). The system was given another 10 minutes of incubation at $36^{\circ} \mathrm{C}$. Confocal measurements of $\Delta \Psi_{\mathrm{m}}$ (with TMRM) and simultaneous video-based myocyte sarcomere length measurements were then performed (see supplementary video). Line-scan confocal imaging was carried out, scanning every $10 \mathrm{~ms}$ along the traverse axis of a single cardiomyocyte with the 561 laser line (Zeiss 880 Airyscan, Germany). Sarcomere length measurements from a live video image at a frame rate of $300 \mathrm{~Hz}$ were carried out using 900B:VSL system (Aurora Scientific, Canada). Field 
electrical stimulation ( $40 \mathrm{Volt} / \mathrm{cm}$ ) to trigger contraction at either $1 \mathrm{~Hz}$ or $8 \mathrm{~Hz}$ was done using MyoPacer (ION optix, USA).

\section{Synthesis of 4-armed PEG-boronic acid}

With stirring, "4-ArmPEG-NH 2 " (nominal MW 5,000, Biochempeg Scientific; $1 \mathrm{~g}, ~ 2.0 \times$ $10^{-4} \mathrm{~mol}$ ) was dissolved in dry $\mathrm{N}, \mathrm{N}$-dimethylformamide (DMF, dried over $\mathrm{CaH}_{2} ; 3 \mathrm{~mL}$ ). Diisopropylethylamine (DIPEA; $0.550 \mathrm{~mL}, 3.16 \times 10^{-3} \mathrm{~mol}$ ) and 4-carboxyphenylboronic acid $\left(0.262 \mathrm{~g}, 1.58 \times 10^{3} \mathrm{~mol}\right)$ were added sequentially to the stirred solution. Thereafter, $1-$ [bis(dimethylamino)methylene]-1 $H$-benzotriazolium hexafluorophosphate 3-oxide (HBTU; $0.599 \mathrm{~g}, 1.58 \times 10^{3} \mathrm{~mol}$ ) was added and stirring of the reaction mixture was continued under argon. As the reaction progressed, the viscosity of the mixture increased. To achieve steady stirring required incremental additions of dry DMF totaling $20 \mathrm{~mL}$. The reaction mixture was stirred for $20 \mathrm{hr}$ after reagent addition was complete. Thereafter, the mixture was added gradually to vigorously stirred anhydrous ethyl ether $(400 \mathrm{~mL})$, whereupon a solid was deposited on the walls of the flask. After stirring for another $20 \mathrm{~min}$, the clear ether solution was decanted and discarded. The deposited solid was rinsed with anhydrous ether $(2 \times 50$ $\mathrm{mL}$ ). The flask containing the solid residue was purged with a gentle stream of nitrogen to drive off residual ether. The solid residue was dissolved in water $(38 \mathrm{~mL})$ to give a slightly turbid, light yellow solution, which was filtered to remove fine particulates. The filtrate was rapidly frozen in liquid $\mathrm{N}_{2}$ and lyophilized to yield a yellow gel. The gel was dissolved in water $(8 \mathrm{~mL}$ ), transferred into dialysis tubing (Float-A Lyser G2, MWCO $100-500 \mathrm{Da}$; Spectrum Laboratories), and dialyzed at room temperature against water ( $2 \mathrm{~L}, 18 \mathrm{M} \Omega \cdot \mathrm{cm})$. The water was changed three times; each change was made after $24 \mathrm{hr}$ of dialysis. The content of the dialysis tubing was transferred into a flask, flash-frozen in liquid $\mathrm{N}_{2}$, and lyophilized to yield a light-yellow solid $(1.282 \mathrm{~g}, \sim 92 \%$ yield). The product was stored under argon at $-20{ }^{\circ} \mathrm{C}$ until use. The $400 \mathrm{MHz}{ }^{1} \mathrm{H}-\mathrm{NMR}$ spectrum of the 4-armed PEG-boronic acid, recorded in DMSO- $d_{6}$, is shown in Supplementary Figure 1. The spectrum shows the expected resonances corresponding to the phenylboronbic acid moieties at the termini of the

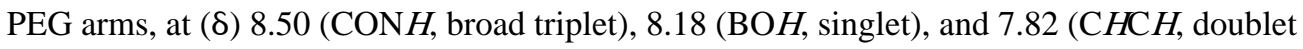
of doublets). Also observed is the expected broad resonance at 3.50, corresponding to the numerous ethylene linkages in the PEG arms.

\section{Synthesis of succinic acid bis(acetoxymethyl) ester ("diAM succinate")}

Succinic acid bis(acetoxymethyl) ester (structure shown in Supplementary Figure 2) was synthesized by alkylation of the dicarboxylate formed in situ with bromomethyl acetate ${ }^{34,35}$. In brief, succinic acid was first treated with 2 equivalents of tetra- $n$ butylammonium hydroxide ( $40 \%$ solution in methanol); volatile solvent was removed by rotary evaporation, and the residue was dried overnight under vacuum. The residue was dissolved in dry DMSO; to this solution were added 2 equivalents of diisopropylethylaimine and 4 equivalents of bromomethyl acetate. The reaction was allowed to proceed at $70^{\circ} \mathrm{C}$ under inert gas for $5 \mathrm{~h}$. The DMSO was removed under vacuum and the residue was taken up in $2 \mathrm{M} \mathrm{KHSO}_{4}$ and extracted with ethyl acetate. The extract was dried $\left(\mathrm{Na}_{2} \mathrm{SO}_{4}\right)$, filtered, and reduced by rotary evaporation to a residue, which was purified by flash chromatography on silica gel (35\% ethyl acetate in hexane as eluant) to yield the diAM ester as a white solid. The $400 \mathrm{MHz}{ }^{1} \mathrm{H}-$ NMR spectrum of diAM succinate, acquired in $\mathrm{CDCl}_{3}$, is shown in Supplementary Figure 2; 
the spectrum shows the three expected singlet resonances at $(\delta) 5.75\left(\mathrm{OCH}_{2} \mathrm{O}\right), 2.71$ $\left(\mathrm{CH}_{2} \mathrm{CH}_{2}\right)$, and $2.12\left(\mathrm{CH}_{3} \mathrm{CO}\right)$. High-resolution mass spectrometry (ESI+ mode) showed a base peak at 263.07703, corresponding to $[\mathrm{M}+\mathrm{H}]^{+}, \mathrm{C}_{10} \mathrm{H}_{15} \mathrm{O}_{8}$, which requires 263.076695 .

\section{Cardiomyocyte $\left[\mathrm{Ca}^{2+}\right]_{\mathrm{m}}$ and $\left[\mathrm{Ca}^{2+}\right]_{\mathrm{i}}$ Measurements.}

Cardiomyocytes were perfused throughout experiments with a normal Tyrode's (NT) bath solution containing (in $\mathrm{mM}$ ): $\mathrm{KCl} 5$, HEPES 5, glucose 5.5, $\mathrm{MgCl}_{2} 0.5, \mathrm{NaCl} 140, \mathrm{NaH}_{2} \mathrm{PO}_{4}$ $0.33, \mathrm{CaCl}_{2} 1.8$, and Cytochalasin-D 0.08, adjusted to $\mathrm{pH} 7.4$ with $\mathrm{NaOH}$. A whole-cell voltage-clamp protocol was used for electric triggering of $\left[\mathrm{Ca}^{2+}\right]_{\mathrm{i}}$ transients (EPC10, HEKA Elektronik, Germany). The membrane potential of a patched cardiomyocyte was stepped from a holding potential of $-80 \mathrm{mV}$ to $0 \mathrm{mV}$ for $100 \mathrm{~ms}$ every two seconds $(0.5 \mathrm{~Hz})$. Microelectrode pipettes (Series Resistance 1.7-2.2 M 2 ) were filled with an intracellular solution containing (in $\mathrm{mM}$ ): $\mathrm{KCl} 20, \mathrm{~K}$ aspartate 100 , tetraethylammonium chloride 20 , HEPES $10, \mathrm{MgCl}_{2} 4.5$, di-sodium ATP 4, di-sodium creatine phosphate 1, Rhod-2, Tripotassium Salt, $0.05, \mathrm{pH}$ 7.2. To simultaneously measure $\left[\mathrm{Ca}^{2+}\right]_{\mathrm{m}}$ and $\left[\mathrm{Ca}^{2+}\right]_{\mathrm{i}}$, confocal line-scan imaging was carried-out along the transverse axes of a patch-clamped cardiomyoytes. $\left[\mathrm{Ca}^{2+}\right]_{\mathrm{m}}$ was measured using a mitochondrial targeted $\mathrm{Ca}^{2+}$-sensitive fluorescent protein-probe MityCam ${ }^{36} 48$ hours after adenoviral transduction at $600 \mathrm{MOI}$ (excited by the $488 \mathrm{~nm}$ Aragon laser line, emission $505-530 \mathrm{~nm}$ ), $\left[\mathrm{Ca}^{2+}\right]_{\mathrm{i}}$ was measured with the $\mathrm{Ca}^{2+}$-sensitive fluorescent indicator Rhod-2 (Tripotassium salt) dialyzed into the cytosol via the patch pipette (excited by the $543 \mathrm{~nm}$ Helium-neon laser line, emission 570 $650 \mathrm{~nm}$ ). For calibration of the fluorescence signals, at the end of each trial the patched cardiomyocyte was perfused sequentially with two calibration solution applied via a local micro-perfusion. The first solution was a NT solution devoid of $\mathrm{Ca}^{2+}$ (chelated with $5 \mathrm{mM}$ EGTA) and supplemented with the $\mathrm{Ca}^{2+}$ ionophore, Ionomycin $(2 \mu \mathrm{M})$. The second was a NT solution with $10 \mathrm{mM} \mathrm{Ca}^{2+}$ supplemented with Ionomycin $(2 \mu \mathrm{M})$. For more details about the calibration please see Boyman et. al., $2014^{37} \cdot\left[\mathrm{Ca}^{2+}\right]_{\mathrm{i}}$ in $\mu \mathrm{M}$ is obtained from the measured Rhod-2 fluorescence ( $F_{R h o d}$ ) according to the following equation (8):

$$
\left[\mathrm{Ca}^{2+}\right]_{\mathrm{i}}=K_{\mathrm{d}, \mathrm{R} 2}\left[\mathrm{~F}_{\mathrm{Rhod}}-\mathrm{F}_{\text {Rhod,Min }}\right] /\left[\mathrm{F}_{\text {Rhod,Max }}-\mathrm{F}_{\text {Rhod }}\right] .
$$

where $\mathrm{F}_{\mathrm{Rhod}, M i n}$ is the fluorescence intensity of Rhod-2 in the absence of $\mathrm{Ca}^{2+}, \mathrm{F}_{\mathrm{Rhod} \text {,Max }}$ is the fluorescence of the $\mathrm{Ca}^{2+}$ saturated Rhod-2. The $\mathrm{Ca}^{2+}$ dissociation constant of Rhod-2 $\left(K_{\mathrm{d}, \mathrm{R} 2}\right)$ is taken as $2.5 \mu \mathrm{M}$ (See Extended Data Fig. $2 \mathrm{c}$ ).

$\left[\mathrm{Ca}^{2+}\right]_{\mathrm{m}}$ in $\mu \mathrm{M}$ is obtained from the measured MityCam fluorescence $\left(\mathrm{F}_{\text {MityCam }}\right)$ according to the following using the following equation (9):

$$
\left[\mathrm{Ca}^{2+}\right]_{\mathrm{m}}=K_{\mathrm{d}, \text { MityCam }}\left[\mathrm{F}_{\text {MityCam,Max }}-\mathrm{F}_{\text {MityCam }}\right] /\left[\mathrm{F}_{\text {MityCam }}-\mathrm{F}_{\text {MityCam,Min }}\right] \text {. }
$$

where $\mathrm{F}_{\mathrm{MityCam}, \mathrm{Max}}$ is the fluorescence intensity of MityCam in the absence of $\mathrm{Ca}^{2+}$, $\mathrm{F}_{\mathrm{MityCam}, \mathrm{Min}}$ is the fluorescence of the $\mathrm{Ca}^{2+}$ saturated MityCam. The $\mathrm{Ca}^{2+}$ dissociation constant of MityCam $\left(K_{\mathrm{d}, \mathrm{MityCam}}\right)$ is taken as $0.2 \mu \mathrm{M}$ (See Extended Data Fig. 7a). 


\section{Luminescence measurements of NADH.}

Rhod-2 AM loaded mitochondria ( $2 \mathrm{mg}$ per $\mathrm{mL}$ ) were mixed in assay buffer ( $\mathrm{AB}$ ) consisting of (in mM): KGluconate 130, $\mathrm{KCl} 5, \mathrm{~K}_{2} \mathrm{HPO}_{4} 1$ or 10, $\mathrm{MgCl}_{2}$ 1, HEPES 10, EGTA 0.04, BSA $0.5 \mathrm{mg} / \mathrm{mL}$. The mitochondria were incubated for 2 minutes prior to the start of the assay with nominally free- $\mathrm{Ca}^{2+} \mathrm{AB}$ or with $\mathrm{AB}$ supplanted with $\mathrm{Ca}^{2+}$ (to raise $\left[\mathrm{Ca}^{2+}\right]_{\mathrm{m}}$ to > $2 \mu \mathrm{M}$ ) and metabolic substrates (either $1 \mathrm{mM}$ pyruvate $+0.5 \mathrm{mM}$ malate, or $1 \mathrm{mM}$ glutamate $+0.5 \mathrm{mM}$ malate, or $0.1 \mathrm{mM}$ palmitoylcarnitine $+2.5 \mathrm{mM}$ malate). The $\left[\mathrm{Ca}^{2+}\right]_{\mathrm{m}}$ was measured, and mitochondria were mixed with $500 \mu \mathrm{M}$ ADP for one minute before flash frozen by dipping the mitochondria samples in liquid nitrogen. The subsequent procedures and NADH measurements were carried out with a luminescence assay kit according to the manufacturer protocol (Promega, USA). All luminescence and fluorescence measurements were carried out with a BMG LABTECH CLARIOstar plate reader.

\section{Statistics.}

All results are presented as mean \pm s.e.m. All experiments were repeated independently with at least three separate sample preparations. All experiments require fresh heart tissue, thus statistical analysis was carried out in parallel with experiments to determine when further repetition was no longer required. Statistical analysis was performed using either OriginPro 2018 or Matlab R2016a statistical package all with $a=0.05$. Where appropriate, column analyses were performed using an unpaired, two-tailed t-test (for two groups) or one-way ANOVA with Bonferroni correction (for groups of three or more). Data fitting convergence was achieved with a minimal termination tolerance of $10^{-6}$. P values less than $0.05(95 \%$ confidence interval) were considered significant. All data displayed a normal distribution and variance was similar between groups for each evaluation. Detailed statistical information is included as Supplementary Table linked to the online version of this article.

\section{Reporting Summary.}

Further information on research design is available in the Nature Research Reporting Summary linked to this article.

\section{Data availability.}

The data that support the findings of this study are available from the corresponding author upon reasonable request.

\section{Extended Data}



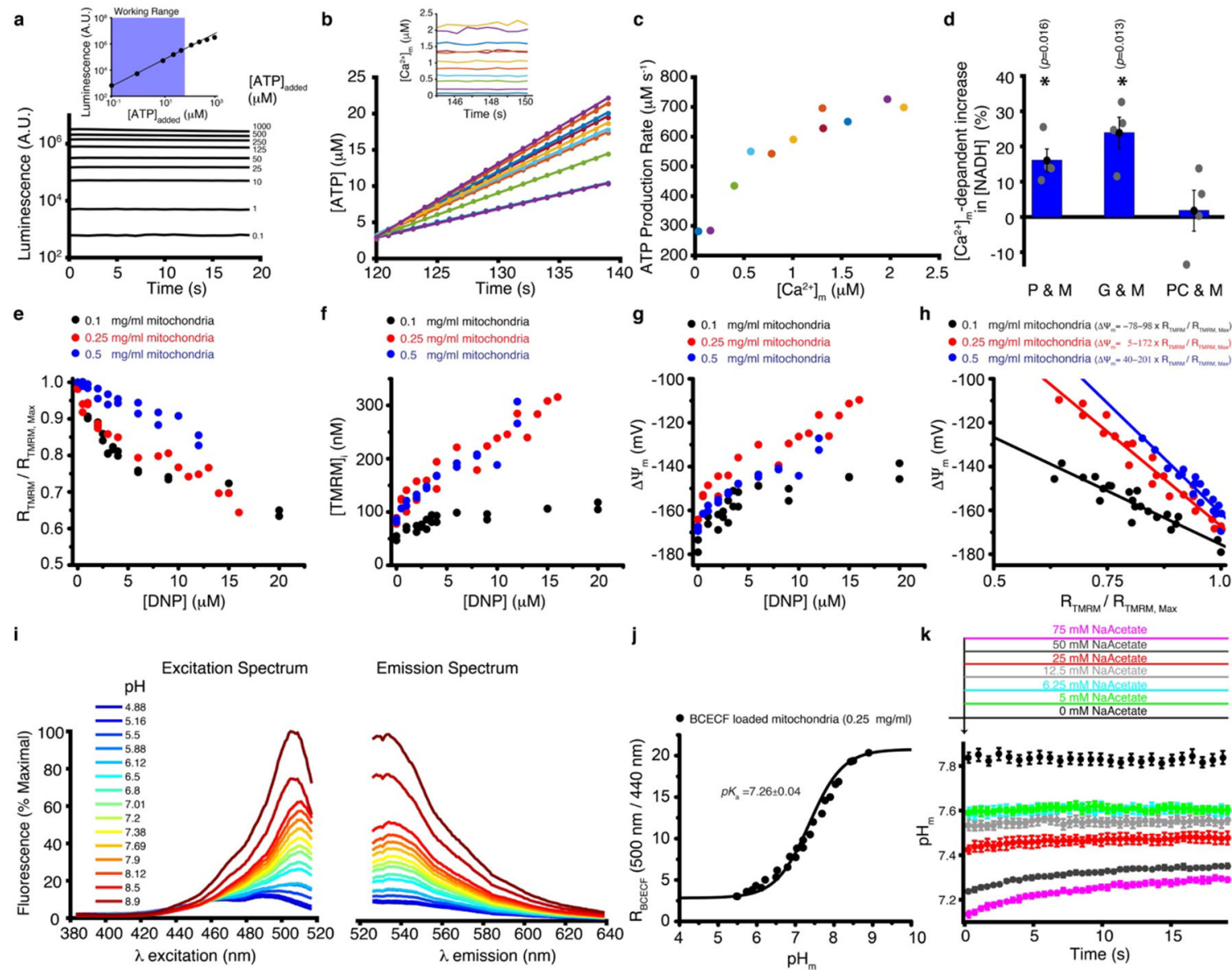

Extended Data Figure 1. Mitochondrial ATP production, NADH, voltage, and pH.

a. Time-course of fire-fly Luciferase luminescence signal measured from 9 wells after addition of ATP to each well. In this calibration procedure, different amounts of [ATP] are added to each of the 9 wells as indicated to the right of each line ([ATP $]_{\text {added }}$ in $\left.\mu \mathrm{M}\right)$. The inset shows the measured luminescence versus $[\mathrm{ATP}]_{\text {added }}$. Purple shaded area highlights the "Working Range" in which the luminescence signal is a linear function of [ATP]. b. Measurements of [ATP] produced by isolated mitochondria. The calibration procedure shown in (a) is used to convert the measured luminescence signal to [ATP]. The inset shows the measured mitochondrial matrix free $\mathrm{Ca}^{2+}$ concentration $\left(\left[\mathrm{Ca}^{2+}\right]_{\mathrm{m}}\right)$ associated with the ATP measurements in (b). c. ATP production rate based on the linear fit to measurements in (b) and scaled to units of $\mu \mathrm{mol}$ per liter cytosol per second ( $\mu \mathrm{M} \mathrm{s}^{-1}$, scaling is based on $80 \mathrm{~g}$ mitochondrial protein per liter cardiomyocyte cytosol, for more details see main methods section and Williams et. al., 2014). d. The increase in $[\mathrm{NADH}]$ at high $\left[\mathrm{Ca}^{2+}\right]_{\mathrm{m}}(>2 \mu \mathrm{M})$ relative to $[\mathrm{NADH}]$ at low $\left[\mathrm{Ca}^{2+}\right]_{\mathrm{m}}(<200 \mathrm{nM})$ using the indicated combination of carbon substrates (P\&M, Pyruvate and Malate; G\&M, Glutamate and Malate; PC\&M, PalmitoylCarnitine and Malate, $\mathrm{n}=4$ isolated mitochondria preparations per group, * $\mathrm{P}<$ 0.05 by two-sided t-test). Data are mean \pm s.e.m. $\left[\mathrm{Ca}^{2+}\right]_{\mathrm{m}}$ was measured with Rhod- 2 .

$[\mathrm{NADH}]$ measurements were carried out with a luminescence assay kit (Promega, USA, for additional details see Supplementary Methods section 1.4). e. Measured TMRM fluorescence ratio $\left(\mathrm{F}_{573} / \mathrm{F} 46\right)$ over the maximal fluorescence ratio from the dataset. 
Mitochondria are exposed to 2,4-dinitrophenol ([DNP] in $\mu \mathrm{M}$ ) as indicated. f. Measured extra-mitochondrial TMRM concentration. $\mathbf{g}$. The mitochondrial inner membrane potential $\left(\Delta \Psi_{\mathrm{m}}\right)$ in $\mathrm{mV}$ is obtained from the measurements in (f) according to the method by Scaduto RC \& Grotyohann LW 1999. h. $\Delta \Psi_{\mathrm{m}}$ and its corresponding TMRM fluorescence ratio.

Linear fit lines are as indicated in the inset. The calibration results shown in panels e-h were verified repeatedly on a daily bases with similar results obtained. i. Excitation and emission spectra of mitochondria loaded with BCECF $\left(2^{\prime}, 7^{\prime}\right.$-bis(2-carboxyethyl)-5(6)-

carboxyfluorescein acetoxymethyl ester). 15 independents measurements are shown at the indicated $\mathrm{pH}$ levels $\left(1 \mu \mathrm{M}\right.$ FCCP is used to equilibrate $\mathrm{pH}_{\mathrm{m}}$ and the extra-mitochondrial buffer $\mathrm{pH}$ ) with the similar spectrum shown. $\mathbf{j}$. Measured fluorescence ratio from BCECFloaded mitochondria at the indicated mitochondrial $\mathrm{pH}$ values $\left(\mathrm{pH}_{\mathrm{m}}\right)$. The calibration was verified in two mitochondrial preps with similar results obtained $\mathbf{k}$. The $\mathrm{pH}_{\mathrm{m}}$ measurements following exposure to sodium acetate at the indicated concentrations. Data are mean \pm s.e.m. (Results are from 3 independent experiments in each of the indicated 7 concentrations of sodium acetate). 
a

- Fluo-4 in Assay Buffer without MgC - Fluo-4 in Assay Buffer without $\mathrm{PO}_{4}$

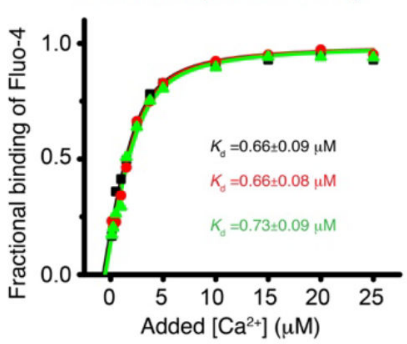

b

- Fluo-4FF in Assay Buffer

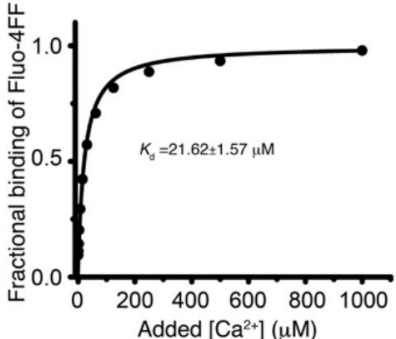

Rhod-2 in Assay Buffer
- Rhod-2 in Assay Buffer $+1.5 \%$ PVP

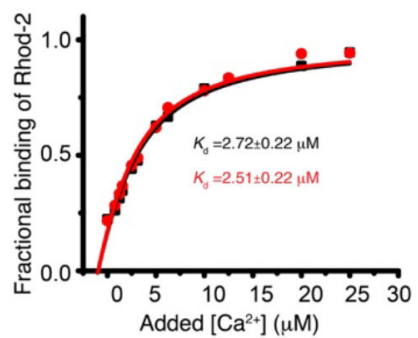
- Fura-2 AM loaded mitochondria

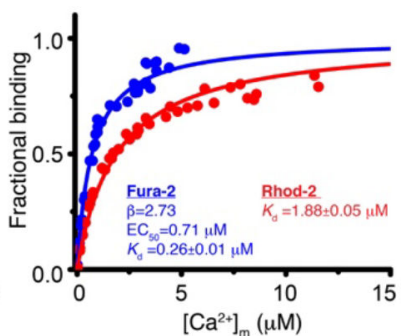

Extended Data Figure 2. Calibration of fluorescence measurements with $\mathrm{Ca}^{2+}$ indicators. a. Fluo-4 $\mathrm{Ca}^{2+}$ titration curve. Shown is the fraction of $\mathrm{Ca}^{2+}$-bound Fluo-4 bound at the indicated added $\left[\mathrm{Ca}^{2+}\right]$. Each point is a triplicate average. Titration curves are carried out in the indicated buffers. b. Fluo-4FF Ca ${ }^{2+}$ titration curve. Shown is the fraction of $\mathrm{Ca}^{2+}$-bound Fluo-4FF at the indicated added $\left[\mathrm{Ca}^{2+}\right]$. Each point is a triplicate average. $\mathbf{c}$. $\mathrm{Rhod}-2 \mathrm{Ca}^{2+}$ titration curve. Shown is the fraction of $\mathrm{Ca}^{2+}-$ bound Rhod-2 at the indicated added $\left[\mathrm{Ca}^{2+}\right]$. Each point is a triplicate average. Titration is done in the absence and presence of PVP (polyvinylpyrrolidone) in the assay buffer. d. $\mathrm{Ca}^{2+}$ titration curve for Fura-2AM- or Rhod-2AM-loaded mitochondria. Shown is the fraction of $\mathrm{Ca}^{2+}$-bound Fura-2 or Rhod-2 at the indicated free $\mathrm{Ca}^{2+}$ concentration in the mitochondrial matrix $\left(\left[\mathrm{Ca}^{2+}\right]_{\mathrm{m}}\right)$. Each point is a triplicate average. $1 \mu \mathrm{M}$ FCCP and $1 \mu \mathrm{M}$ of the $\mathrm{Ca}^{2+}$ ionophore ionomycin are used to equilibrate $\left[\mathrm{Ca}^{2+}\right]_{\mathrm{m}}$ with the extra-mitochondrial free $\left[\mathrm{Ca}^{2+}\right]$ (i.e., $\left[\mathrm{Ca}^{2+}\right]_{\text {extra, free). The }}$

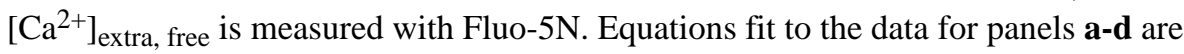
detailed in the main methods section. 
a

- Pyruvate \& Malate $+5 \mu \mathrm{M}$ Ru360

- Glutamate \& Malate +5 uM Ru360

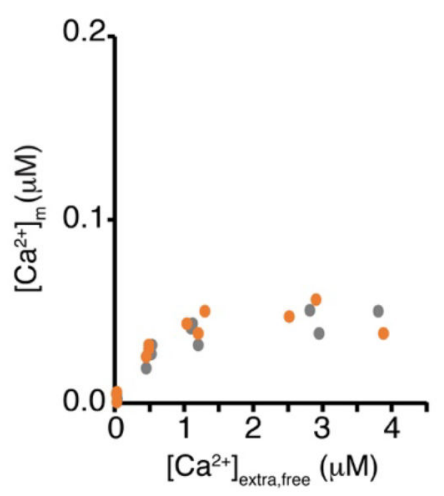

b

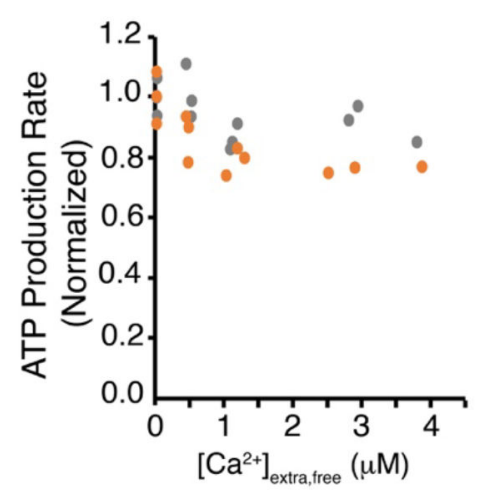

c

Pyruvate \& Malate $+5 \mu \mathrm{M}$ Ru360

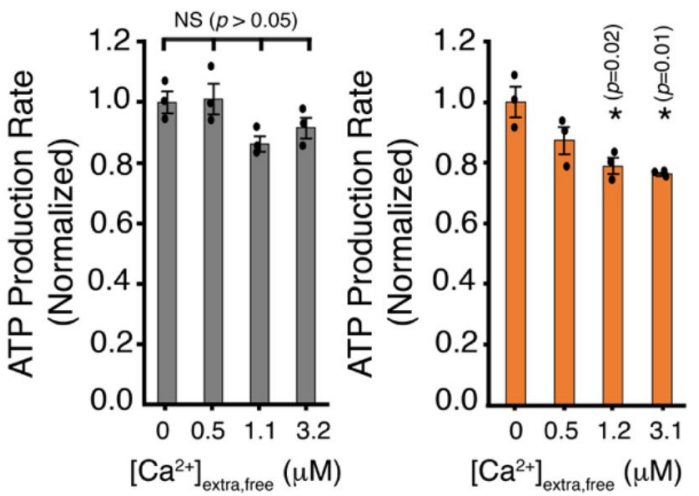

Extended Data Figure 3. Measurements of mitochondrial ATP production when the MCU is blocked by RU360.

a. Measurements of $\left[\mathrm{Ca}^{2+}\right]_{\mathrm{m}}$ in isolated cardiac mitochondria plotted as a function of the measured free extramitochondrial $\left[\mathrm{Ca}^{2+}\right]$ (i.e., $\left[\mathrm{Ca}^{2+}\right]_{\text {extra,free}}$ ) in the presence of the selective MCU blocker RU360 (5 $\mu \mathrm{M})$. Grey circles are measurements done in the presence of pyruvate $(1 \mathrm{mM}) \&$ malate $(0.5 \mathrm{mM}) . n=12$ independent experiments. Orange circles are measurements done in the presence of glutamate $(1 \mathrm{mM}) \&$ malate $(0.5 \mathrm{mM}) . n=12$ independent experiments. $\left[\mathrm{Ca}^{2+}\right]_{\mathrm{m}}$ was measured with Fura-2 loaded into the mitochondrial

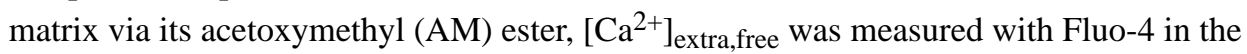
extra mitochondrial buffer. b. Measurements of ATP production plotted as a function of the

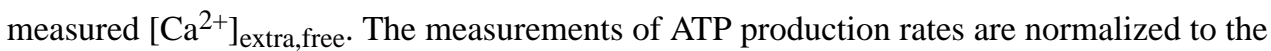
measurements at nominally zero $\left[\mathrm{Ca}^{2+}\right]_{\text {extra,free }}$ c. ATP production at the indicated measured $\left[\mathrm{Ca}^{2+}\right]_{\text {extra,free }}$ (from experiments in a-b). Grey bars (left) are ATP production with pyruvate $\&$ malate. Orange bars (right) are ATP production with glutamate \& malate. Data are mean \pm s.e.m. $\mathrm{n}=3$ isolated mitochondria preparations per group, $* \mathrm{P}<0.05$ by one-way two tailed ANOVA with Bonferroni correction). 


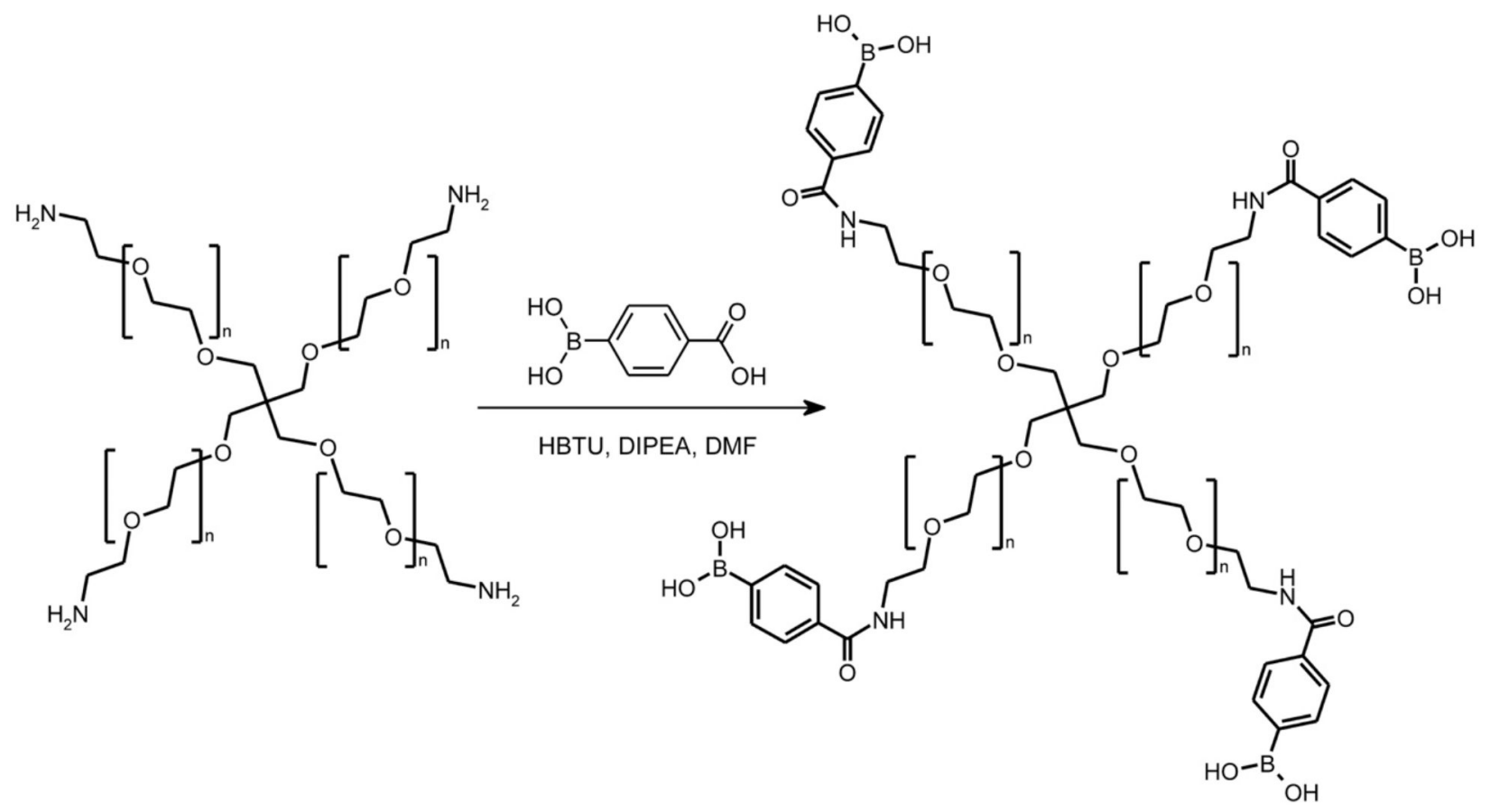

Extended Data Figure 4. Synthesis of 4-armed PEG-boronic acid.

Abbreviations used: HBTU, 1-[bis(dimethylamino)methylene]-1 $H$-benzotriazolium hexafluorophosphate 3-oxide; DIPEA, diisopropylethylamine; DMF, $N, N$ -

dimethylformamide. The detailed description of the synthesis procedure is in the methods section. 
a

b
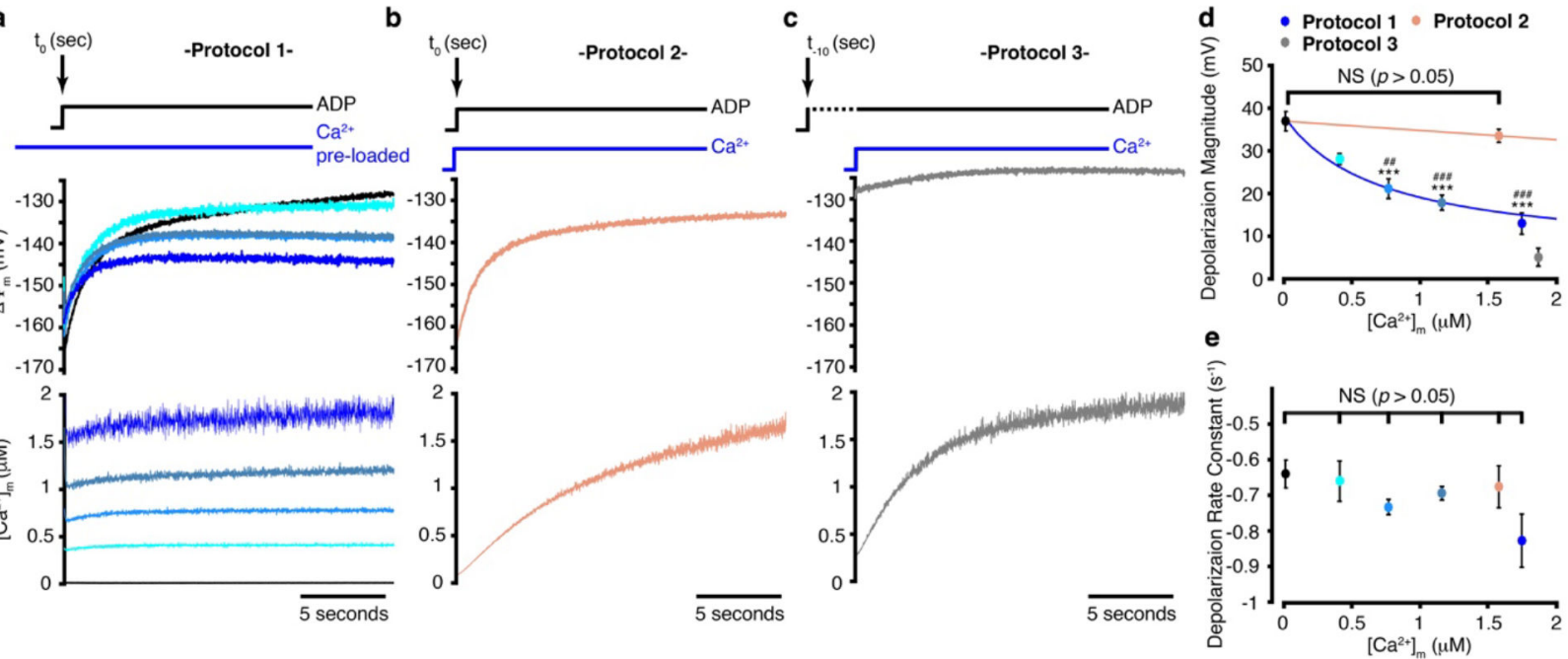

Extended Data Figure 5. $\Delta \Psi_{\mathrm{m}}$ kinetics during mitochondrial ATP production.

a. Time-dependent stopped-flow measurement of $\Delta \Psi_{\mathrm{m}}$ (upper panel) and of the corresponding $\left[\mathrm{Ca}^{2+}\right]_{\mathrm{m}}$ (lower panel). In this protocol (\#1), mitochondria were incubated with increasing extra-mitochondrial free $\mathrm{Ca}^{2+}$ and at $\mathrm{t}=0,500 \mu \mathrm{M}$ [ADP] was added to the mitochondrial mix. Time-dependent depolarization of $\Delta \Psi_{\mathrm{m}}$ is shown as is the near steadystate of $\left[\mathrm{Ca}^{2+}\right]_{\mathrm{m}}$. Black line: $\left[\mathrm{Ca}^{2+}\right]_{\mathrm{m}}=50 \mathrm{nM}(\mathrm{n}=8)$; turquoise: $\left[\mathrm{Ca}^{2+}\right]_{\mathrm{m}}=480 \mathrm{nM}(\mathrm{n}=3)$; light blue: $\left[\mathrm{Ca}^{2+}\right]_{\mathrm{m}}=750 \mathrm{nM}(\mathrm{n}=6)$; grey-blue: $\left[\mathrm{Ca}^{2+}\right]_{\mathrm{m}}=1.2 \mu \mathrm{M}(\mathrm{n}=8)$; navy blue: $\left[\mathrm{Ca}^{2+}\right]_{\mathrm{m}}=$ $1.7 \mu \mathrm{M}(\mathrm{n}=4)$. b. Same as (a) but in this protocol $(\# 2),\left[\mathrm{Ca}^{2+}\right]_{\mathrm{m}}$ and $[\mathrm{ADP}](500 \mu \mathrm{M})$ were increased simultaneously at $\mathrm{t}=0$ (salmon-colored line, $\mathrm{n}=7$ ). The injected $\mathrm{Ca}^{2+}$ was set so that the $\left[\mathrm{Ca}^{2+}\right]_{\mathrm{m}}$ achieved a level between 1.5 and $2 \mu \mathrm{M}$ at $20 \mathrm{~s}$. c. Same as (b) but in this protocol (\#3), [ADP] $(500 \mu \mathrm{M})$ rises 10 seconds before $\left[\mathrm{Ca}^{2+}\right]_{\mathrm{m}}$ was increased at $\mathrm{t}=0$ (grey line, $\mathrm{n}=6)$. The injected $\mathrm{Ca}^{2+}$ was set so that the $\left[\mathrm{Ca}^{2+}\right]_{\mathrm{m}}$ achieved a level between 1.5 and 2 $\mu \mathrm{M}$ at $20 \mathrm{~s}$, gray line. In panels a-c the sample size (n) represent the number of independent experiments. d. The magnitude of $\Delta \Psi_{\mathrm{m}}$ depolarization in experiments a-c. The sample size is the same as in panels a-c. (* and ${ }^{\#}$ denotes statistical comparisonto black and beige data, respectively). e. Exponential rate constant of $\Delta \Psi_{\mathrm{m}}$ depolarization in experiments a-b. The sample size is the same as in panels a-b. In d-e data are mean \pm s.e.m. $* \mathrm{P}<0.05, * * \mathrm{P}<0.01$, $* * * \mathrm{P}<0.001$ by one-way two-tailed ANOVA with Bonferroni correction. 

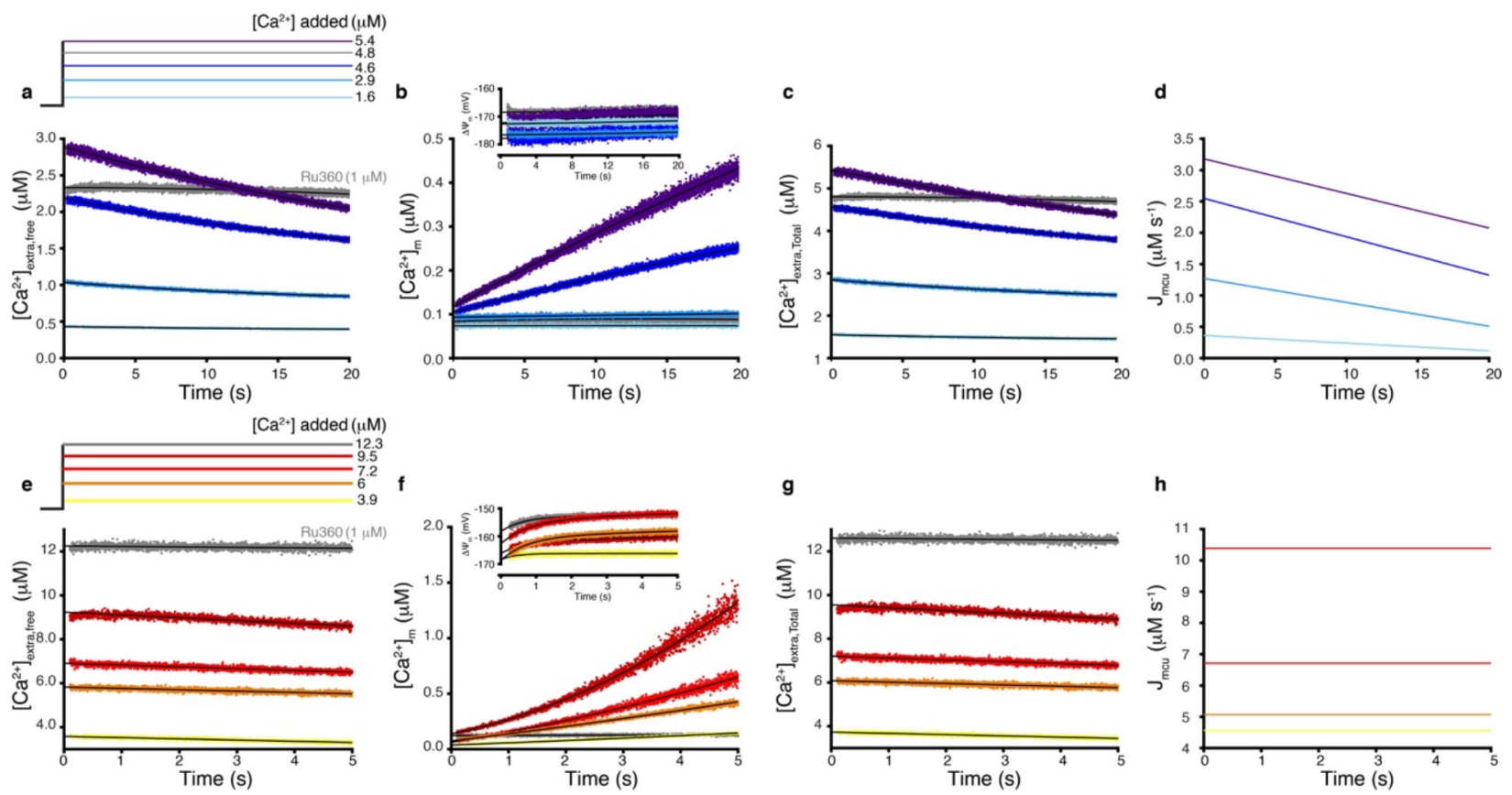

Extended Data Figure 6. Stopped-flow measurements of $\mathrm{MCU} \mathrm{Ca}^{2+}$ flux and its driving force. a and e. Representative stopped-flow time-dependent measurements of extra-mitochondrial

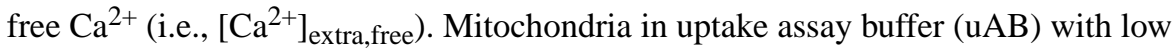
$\left[\mathrm{Ca}^{2+}\right]_{\text {extra,free }}(<100 \mathrm{nM})$ are mixed with $\mathrm{uAB}$ buffer with added $\left[\mathrm{Ca}^{2+}\right] 1 \mathrm{~ms}$ before fluorescence measurements begin. The levels of added $\left[\mathrm{Ca}^{2+}\right]$ are set so that at the beginning of the measurements the $\left[\mathrm{Ca}^{2+}\right]$ added will be as indicated in the inset. In (a) $\left[\mathrm{Ca}^{2+}\right]_{\text {extra,free }}$ is measured with Fluo-4 in the $\mathrm{UAB}$ and in (e) with Fluo-4FF. $\mathbf{b}$ and $\mathbf{f}$. The corresponding time-dependent measurements of matrix free $\mathrm{Ca}^{2+}\left(\right.$ i.e., $\left.\left[\mathrm{Ca}^{2+}\right]_{\mathrm{m}}\right)$. Insets showing the corresponding time-dependent measurements of $\Delta \Psi_{\mathrm{m}}$. $\mathbf{c}$ and $\mathbf{g}$. The corresponding timedependent measurements of total extra-mitochondrial $\mathrm{Ca}^{2+}\left(\left[\mathrm{Ca}^{2+}\right]_{\text {extra,Total }}\right)$. The $\left[\mathrm{Ca}^{2+}\right]_{\text {extra,Total }}$ is obtained from the Fluo-4 or Fluo-4FF signals (for more details see the methods section). $\mathbf{d}$ and $\mathbf{h}$. MCU Ca ${ }^{2+}$ influx $\left(\mathrm{J}_{\mathrm{mcu}}\right)$ is the first derivative of the $\left[\mathrm{Ca}^{2+}\right]_{\text {extra,Total }}$. The $\mathrm{J}_{\text {mcu }}$ is scaled to units of $\mu \mathrm{mol}$ per liter cytosol per second $\left(\mu \mathrm{M} \mathrm{s}^{-1}\right.$, scaling is based on $80 \mathrm{~g}$ mitochondrial protein per liter cardiomyocyte cytosol, for more details see main methods section and Williams et. al., 2014). The shown stopped flow experiments were repeated independently 63 times with similar results at each $\left[\mathrm{Ca}^{2+}\right]_{\text {extra,free }}$ as indicated in Fig 3 a. 
a

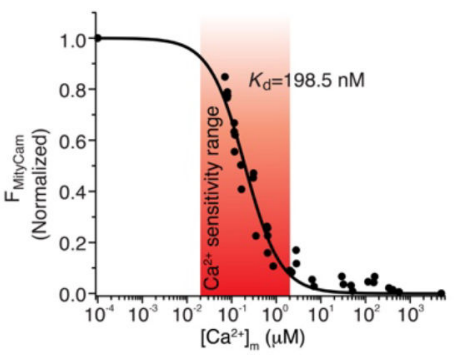

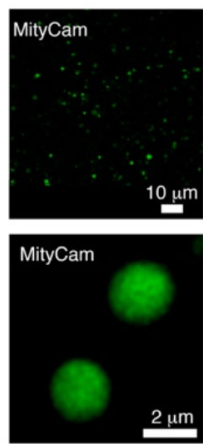

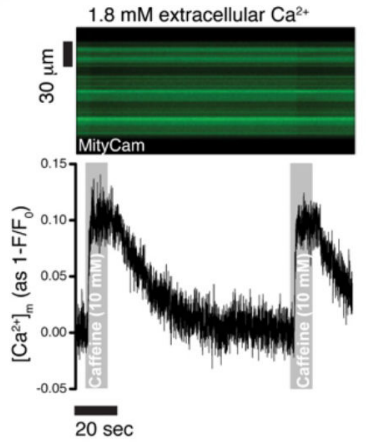

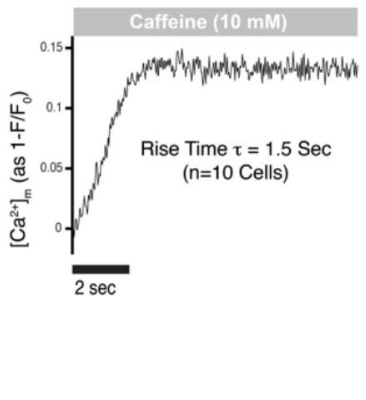

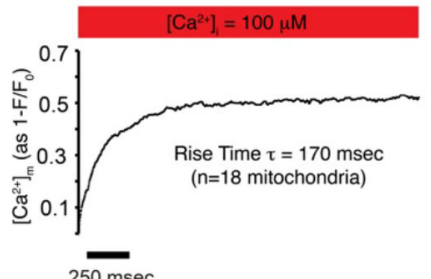

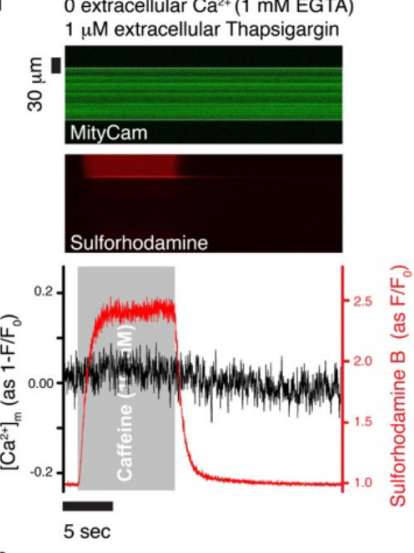

h

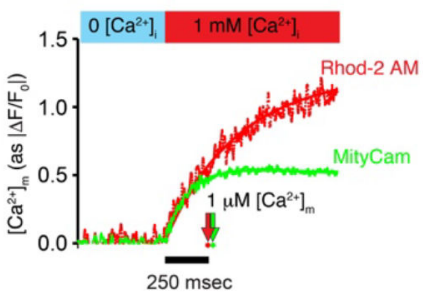

Extended Data Figure 7. Characterization of MityCam; a mitochondrially targeted $\mathrm{Ca}^{2+}$. sensitive fluorescent-protein probe expressed in heart muscle cells.

a. MityCam fluorescence versus $\left[\mathrm{Ca}^{2+}\right]_{\mathrm{m}}$. Note that $\mathrm{Ca}^{2+}$ binding decreases MityCam fluorescence. Measurements are in saponin-permeabilized cardiomyocytes; $\left[\mathrm{Ca}^{2+}\right]_{\mathrm{m}}$ is set using the $\mathrm{Ca}^{2+}$ ionophore ionomycin $(2 \mu \mathrm{M})$. The extracellular (bath) solution contains Rhod-2 (tripotassium salt, cell-impermeant) to measure the bath $\left[\mathrm{Ca}^{2+}\right]$, a proton ionophore carbonyl cyanide m-chlorophenyl hydrazone (CCCP, $500 \mathrm{nM})$ to set the mitochondrial $\mathrm{pH}$, rotenone $(400 \mathrm{nM})$ to block the ETC and the production of ROS, and oligomycin $(5 \mathrm{mM})$ to block reverse-mode consumption of ATP by the ATP synthase, $\mathrm{pH}$ 7.8. Fit curve is a singlesite binding model ( $n=30$ cells). b. Top: Confocal line-image from an intact cardiomyocyte expressing MityCam. Bottom: The time-course of changes in $\left[\mathrm{Ca}^{2+}\right]_{\mathrm{m}}$ from the confocal fluorescence measurements. Caffeine $(10 \mathrm{mM})$ was applied for 10 seconds via a local microperfusion system to rapidly trigger $\mathrm{Ca}^{2+}$ release from the sarcoplasmic reticulum at the indicated times (highlighted with gray shading). The experiment was repeated independently with $n=10$ cells with similar results. c. The average time-course of changes in $\left[\mathrm{Ca}^{2+}\right]_{m}$ following caffeine applications. d. Confocal line-image from an intact cardiomyocyte expressing MityCam in a bath solution devoid of $\mathrm{Ca}^{2+}$ (chelated by $1 \mathrm{mM}$ EGTA) and treated with thapsigargin $(1 \mu \mathrm{M})$ for 10 minutes prior to imaging to deplete the sarcoplasmic reticulum of $\mathrm{Ca}^{2+}$. Top panel shows MityCam fluorescence; middle panel shows the fluorescence of sulforhodamine (sulforhodamine is included in the micro-perfusion solution to indicate the exact duration of $10 \mathrm{mM}$ caffeine application). Lower panel shows the timecourse of changes in $\left[\mathrm{Ca}^{2+}\right]_{\mathrm{m}}$ from the confocal fluorescence measurements. Note that throughout the entire time course of the experiment the extracellular solution is devoid of 
$\mathrm{Ca}^{2+}$ and also contains $1 \mu \mathrm{M}$ thapsigargin. The experiment was repeated independently with $\mathrm{n}=11$ cells with similar results. e. Confocal images of cardiac mitochondria isolated from MityCam expressing cardiomyocytes. f. Measurements of $\left[\mathrm{Ca}^{2+}\right]_{\mathrm{m}}$ from isolated single mitochondria expressing MityCam. Top panel (i) shows MityCam fluorescence; lower panel (ii) shows sulforhodamine fluorescence, which indicates the duration of micro-perfusion of $100 \mathrm{M} \mathrm{Ca}^{2+}$ (see bars above the top panel). Mitochondria isolated from MityCamexpressing cardiomyocytes are adhered to a glass coverslip for confocal microscopy measurements. Rapid step (2-3 ms rise time) of $\left[\mathrm{Ca}^{2+}\right]$ from 0 ( $1 \mathrm{mM}$ EGTA) to $100 \mu \mathrm{M}$ is achieved via a micro-perfusion system. Sulforhodamine is included in the solution applied via the micro-perfusion system to indicate when a mitochondrion is exposed to the solution containing $100 \mu \mathrm{M} \mathrm{Ca}^{2+}$. The experiment in e-f were repeated independently with $\mathrm{n}=18$ mitochondria with similar results. g. the average time-course of changes in $\left[\mathrm{Ca}^{2+}\right]_{\mathrm{m}}$ following the step increase of $\mathrm{Ca}^{2+}$ from 0 to $100 \mu \mathrm{M}$ (black line). h. Same as (g) but for comparison to another $\mathrm{Ca}^{2+}$ sensitive fluorescent indicator, MityCam-expressing mitochondria are also loaded with the fluorescent $\mathrm{Ca}^{2+}$ indicator Rhod-2 via its acetoxymethyl (AM) ester form (Rhod-2 AM). To accelerate the rate of $\left[\mathrm{Ca}^{2+}\right]_{\mathrm{m}}$ rise $\left[\mathrm{Ca}^{2+}\right]$ is raised to $1 \mathrm{mM}$, all solutions also contain ionomycin $(5 \mu \mathrm{M})$, FCCP $(5 \mu \mathrm{M})$, oligomycin (1 $\mu \mathrm{M}), \mathrm{pH}=7.8$. Green trace for MityCam ( $n=12$ mitochondria) and red for Rhod-2 ( $n=9$ mitochondria). The time at which $1 \mu \mathrm{M}\left[\mathrm{Ca}^{2+}\right]_{\mathrm{m}}$ is measured is indicated by arrows, this time point is obtained by converting the shown fit lines to units of $\mu \mathrm{M}\left[\mathrm{Ca}^{2+}\right]_{\mathrm{m}}$. For additional details see Boyman et al., 2014. 
a - Heart

- Skeletal Muscle

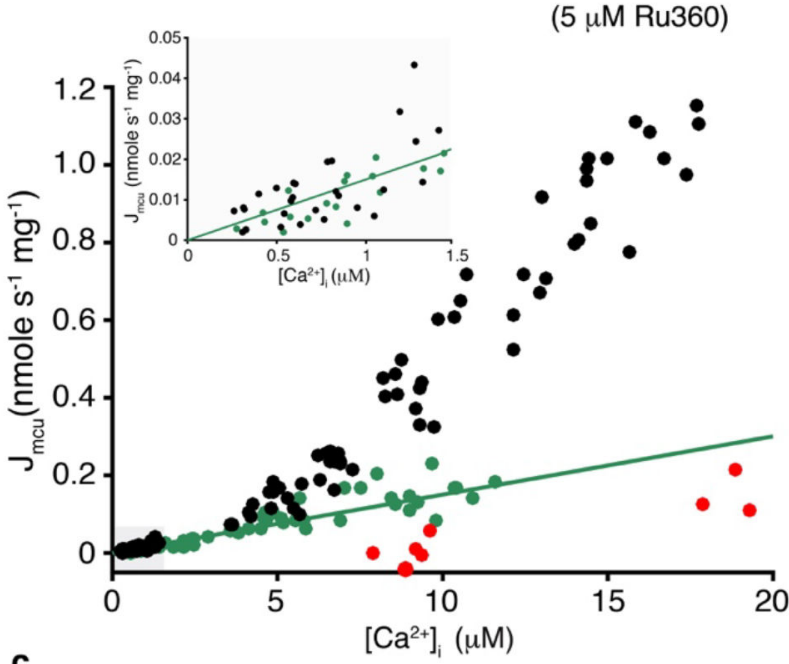

C

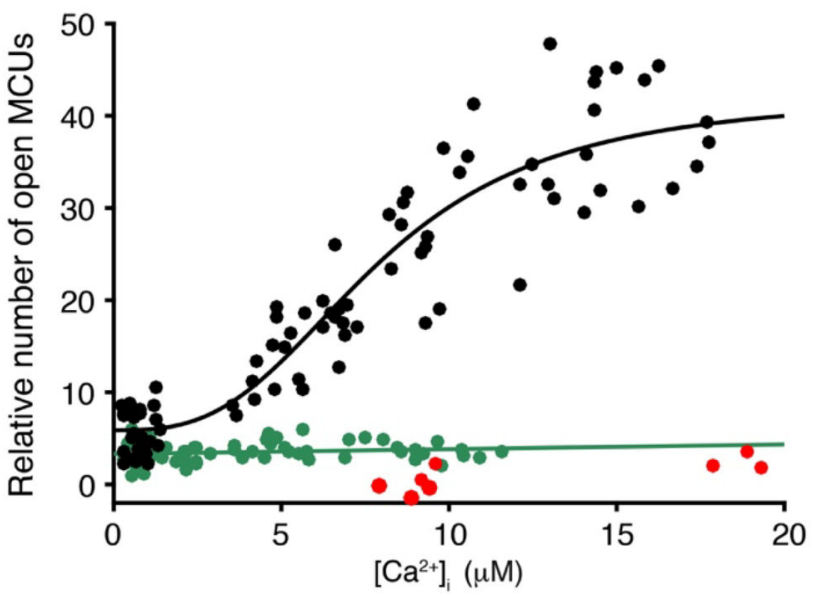

b

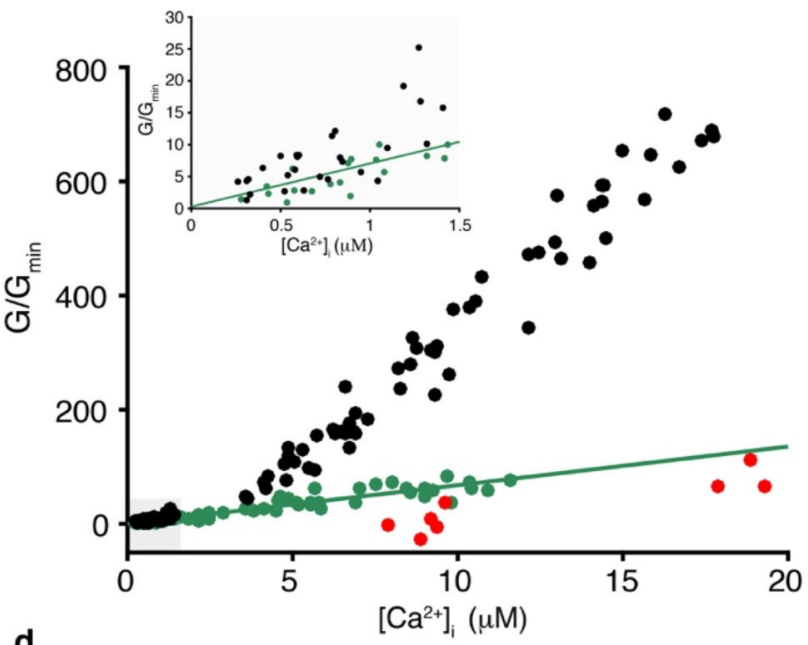

d

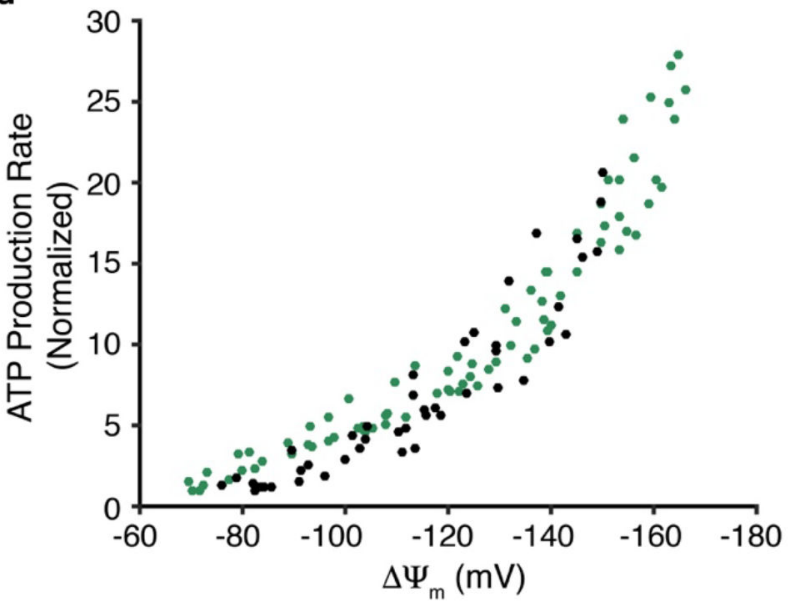

Extended Data Figure 8. MCU conductance and voltage dependence of ATP production in heart and skeletal muscle.

a. Measurement of the MCU-dependent $\mathrm{Ca}^{2+}$ influx $\left(\mathrm{J}_{\mathrm{mcu}}\right)\left(\right.$ nmole $\left.\mathrm{mg}^{-1} \mathrm{~s}^{-1}\right)$ in cardiac mitochondria (green circles, from Fig. 3), skeletal muscle (black circles), and skeletal muscle with $\mathrm{Ru} 360(5 \mu \mathrm{M})$ (red circles) is plotted as a function of measured $\left[\mathrm{Ca}^{2+}\right]_{\mathrm{i}}(\mathrm{n}=63$, $\mathrm{n}=87$, and $\mathrm{n}=12$ independent experiments, respectively, each with $\left[\mathrm{Ca}^{2+}\right]_{\mathrm{i}},\left[\mathrm{Ca}^{2+}\right]_{\mathrm{m}}$ and $\Delta \Psi_{\mathrm{m}}$ measured). Linear least-squares fit to the heart mitochondria data is shown (slope = $0.015)$. b. MCU conductance $(G)$ for each measurement shown in (a) normalized to the minimal conductance $\left(\mathrm{G}_{\min }\right)$ of the cardiac dataset $\left(\mathrm{G} / \mathrm{G}_{\min }\right)$ plotted as a function of $\left[\mathrm{Ca}^{2+}\right]_{\mathrm{i}}$. Linear least-squares fit line to the heart mitochondria data is shown (slope $=6.1$ ). $\mathbf{c}$. Relative number of open MCUs per mitochondrion plotted as a function of $\left[\mathrm{Ca}^{2+}\right]_{\mathrm{i}}$. Taken from (b) after dividing by the $\left[\mathrm{Ca}^{2+}\right]_{i}$-dependent unitary conductance of MCU and normalized to the minimal number of open MCUs of the cardiac dataset. Linear least-squares fit to the heart mitochondria data is shown (slope $=0.051$, intercept $=3.3$ ). For skeletal muscle data under $\left[\mathrm{Ca}^{2+}\right]_{\mathrm{i}}$ of $1.5 \mu \mathrm{M}$ the measurements were done using stopped flow as described in Extended Data Fig $5 . \mathrm{J}_{\mathrm{mcu}}$ at $\left[\mathrm{Ca}^{2+}\right]_{\mathrm{i}}$ above $1.5 \mu \mathrm{M}$ was collected using a multi-well plate reader with $\Delta \Psi_{\mathrm{m}}$ set using a $\mathrm{K}^{+}$gradient and the $\mathrm{K}^{+}$ionophore valinomycin. Skeletal muscle data is fit 
to a modified Hill equation with a $K_{0.5}$ of $7.9 \mu \mathrm{M}$ and a Hill coefficient of 2.95. d. The dependence of ATP production on $\Delta \Psi_{\mathrm{m}}$ in the absence of carbon substrates and at $\left[\mathrm{Ca}^{2+}\right]_{\mathrm{m}}<$ $200 \mathrm{nM}$. The measurements of ATP production rates are normalized to the minimal production rate of each data set. Measurements from heart mitochondria are shown in green circles ( $n=77$, replotted from Fig. 4a), the measurements from skeletal muscle mitochondria are in shown in black circles ( $n=45$ independent experiments). $\Delta \Psi_{\mathrm{m}}$ was set by using a fixed $\mathrm{K}^{+}$gradient and the $\mathrm{K}^{+}$ionophore valinomycin (see Methods).

\section{Supplementary Material}

Refer to Web version on PubMed Central for supplementary material.

\section{Acknowledgments}

We thank B.M. Polster, C.W. Ward, G.S.B. Williams, R.J. Khairallah, and Mariusz Karbowski for helpful suggestions. This research was supported by American Heart Association grants SDG 15SDG22100002 (to L.B.) and 16PRE31030023 (to A.P.W.); By NIH R01 HL106056 and R01 HL105239 and U01 HL116321 (to W.J.L.); By the Medical Scientist Training Program and Training Program in Integrative Membrane Biology, NIH 2T32GM092237-06 and 5T32GM008181-28 (to A.P.W).

\section{References}

1. Fieni F, Lee SB, Jan YN \& Kirichok Y Activity of the mitochondrial calcium uniporter varies greatly between tissues. Nat Commun 3, 1317, doi:10.1038/ncomms2325 (2012). [PubMed: 23271651]

2. Jacobus WE Respiratory control and the integration of heart high-energy phosphate metabolism by mitochondrial creatine kinase. Annu Rev Physiol 47, 707-725, doi:10.1146/annurev.ph. 47.030185.003423 (1985). [PubMed: 3888084]

3. Wang $\mathrm{Z}$ et al. Specific metabolic rates of major organs and tissues across adulthood: evaluation by mechanistic model of resting energy expenditure. Am J Clin Nutr 92, 1369-1377, doi:10.3945/ajcn. 2010.29885 (2010). [PubMed: 20962155]

4. Murphy E et al. Mitochondrial Function, Biology, and Role in Disease: A Scientific Statement From the American Heart Association. Circ Res 118, 1960-1991, doi:10.1161/RES.0000000000000104 (2016). [PubMed: 27126807]

5. DiMauro S \& Schon EA Mitochondrial respiratory-chain diseases. N Engl J Med 348, 2656-2668, doi:10.1056/NEJMra022567 (2003). [PubMed: 12826641]

6. Latorre-Pellicer A et al. Mitochondrial and nuclear DNA matching shapes metabolism and healthy ageing. Nature 535, 561-565, doi:10.1038/nature18618 (2016). [PubMed: 27383793]

7. Williams GS, Boyman L, Chikando AC, Khairallah RJ \& Lederer WJ Mitochondrial calcium uptake. Proc Natl Acad Sci U S A 110, 10479-10486, doi:10.1073/pnas.1300410110 (2013). [PubMed: 23759742]

8. Boyman L, Williams GS \& Lederer WJ The growing importance of mitochondrial calcium in health and disease. Proc Natl Acad Sci U S A 112, 11150-11151, doi:10.1073/pnas.1514284112 (2015). [PubMed: 26311848]

9. Chance B \& Williams GR Respiratory enzymes in oxidative phosphorylation. I. Kinetics of oxygen utilization. J Biol Chem 217, 383-393 (1955). [PubMed: 13271402]

10. Klingenberg M The ADP-ATP translocation in mitochondria, a membrane potential controlled transport. J Membr Biol 56, 97-105 (1980). [PubMed: 7003152]

11. Denton RM, Randle PJ \& Martin BR Stimulation by calcium ions of pyruvate dehydrogenase phosphate phosphatase. Biochem J 128, 161-163 (1972). [PubMed: 4343661]

12. McCormack JG \& Denton RM The effects of calcium ions and adenine nucleotides on the activity of pig heart 2-oxoglutarate dehydrogenase complex. Biochem J 180, 533-544 (1979). [PubMed: 39549] 
13. Glancy B \& Balaban RS Role of mitochondrial Ca2+ in the regulation of cellular energetics. Biochemistry 51, 2959-2973, doi:10.1021/bi2018909 (2012). [PubMed: 22443365]

14. McCormack JG \& Denton RM Mitochondrial Ca2+ transport and the role of intramitochondrial Ca2+ in the regulation of energy metabolism. Dev Neurosci 15, 165-173 (1993). [PubMed: 7805568]

15. Jian Z et al. Mechanochemotransduction during cardiomyocyte contraction is mediated by localized nitric oxide signaling. Sci Signal 7, ra27, doi:10.1126/scisignal.2005046 (2014). [PubMed: 24643800]

16. Mitchell P Coupling of phosphorylation to electron and hydrogen transfer by a chemi-osmotic type of mechanism. Nature 191, 144-148 (1961). [PubMed: 13771349]

17. Brandes R, Maier LS \& Bers DM Regulation of mitochondrial [NADH] by cytosolic [Ca2+] and work in trabeculae from hypertrophic and normal rat hearts. Circ Res 82, 1189-1198 (1998). [PubMed: 9633918]

18. Kirichok Y, Krapivinsky G \& Clapham DE The mitochondrial calcium uniporter is a highly selective ion channel. Nature 427, 360-364, doi:10.1038/nature02246 (2004). [PubMed: 14737170]

19. Bick AG, Calvo SE \& Mootha VK Evolutionary diversity of the mitochondrial calcium uniporter. Science 336, 886, doi:10.1126/science.1214977 (2012). [PubMed: 22605770]

20. Luongo TS et al. The Mitochondrial Calcium Uniporter Matches Energetic Supply with Cardiac Workload during Stress and Modulates Permeability Transition. Cell Rep 12, 23-34, doi:10.1016/ j.celrep.2015.06.017 (2015). [PubMed: 26119731]

21. Kwong JQ et al. The Mitochondrial Calcium Uniporter Selectively Matches Metabolic Output to Acute Contractile Stress in the Heart. Cell reports 12, 15-22, doi:10.1016/j.celrep.2015.06.002 (2015). [PubMed: 26119742]

22. $\mathrm{Wu} \mathrm{Y}$ et al. The mitochondrial uniporter controls fight or flight heart rate increases. Nat Commun 6, 6081, doi:10.1038/ncomms7081 (2015). [PubMed: 25603276]

23. Mallilankaraman K et al. MICU1 is an essential gatekeeper for MCU-mediated mitochondrial $\mathrm{Ca}(2+)$ uptake that regulates cell survival. Cell 151, 630-644, doi:10.1016/j.cell.2012.10.011 (2012). [PubMed: 23101630]

24. Antony AN et al. MICU1 regulation of mitochondrial $\mathrm{Ca}(2+)$ uptake dictates survival and tissue regeneration. Nat Commun 7, 10955, doi:10.1038/ncomms10955 (2016). [PubMed: 26956930]

25. Kaim G \& Dimroth P ATP synthesis by F-type ATP synthase is obligatorily dependent on the transmembrane voltage. EMBO J 18, 4118-4127, doi:10.1093/emboj/18.15.4118 (1999). [PubMed: 10428951]

26. Nguyen MH \& Jafri MS Mitochondrial calcium signaling and energy metabolism. Ann N Y Acad Sci 1047, 127-137, doi:10.1196/annals.1341.012 (2005). [PubMed: 16093491]

27. Dimroth P, von Ballmoos C, Meier T \& Kaim G Electrical power fuels rotary ATP synthase. Structure 11, 1469-1473 (2003). [PubMed: 14656431]

28. Anandakrishnan R, Zhang Z, Donovan-Maiye R \& Zuckerman DM Biophysical comparison of ATP synthesis mechanisms shows a kinetic advantage for the rotary process. Proc Natl Acad Sci U S A 113, 11220-11225, doi:10.1073/pnas.1608533113 (2016). [PubMed: 27647911]

29. Clapham DE Calcium signaling. Cell 131, 1047-1058, doi:10.1016/j.cell.2007.11.028 (2007). [PubMed: 18083096]

30. Cheng H \& Lederer WJ Calcium sparks. Physiol Rev 88, 1491-1545, doi:10.1152/physrev. 00030.2007 (2008). [PubMed: 18923188]

31. Eberhard M \& Erne P Analysis of calcium binding to alpha-lactalbumin using a fluorescent calcium indicator. Eur J Biochem 202, 1333-1338 (1991). [PubMed: 1765086]

32. Scaduto RC Jr. \& Grotyohann LW Measurement of mitochondrial membrane potential using fluorescent rhodamine derivatives. Biophys J 76, 469-477, doi:10.1016/S0006-3495(99)77214-0 (1999). [PubMed: 9876159]

33. De Stefani D, Raffaello A, Teardo E, Szabo I \& Rizzuto R A forty-kilodalton protein of the inner membrane is the mitochondrial calcium uniporter. Nature 476, 336-340, doi:10.1038/nature 10230 (2011). [PubMed: 21685888] 
34. Burks SR et al. (2)H,(15)N-substituted nitroxides as sensitive probes for electron paramagnetic resonance imaging. J. Org. Chem 75, 6463-6467, doi:10.1021/jo1011619 (2010). [PubMed: 20828113]

35. Rosen GM, Burks SR, Kohr MJ \& Kao JP Synthesis and biological testing of aminoxyls designed for long-term retention by living cells. Org. Biomol. Chem 3, 645-648, doi:10.1039/b415586f (2005). [PubMed: 15703801]

36. Terhzaz $\mathrm{S}$ et al. Differential gel electrophoresis and transgenic mitochondrial calcium reporters demonstrate spatiotemporal filtering in calcium control of mitochondria. J Biol Chem 281, 1884918858, doi:10.1074/jbc.M603002200 (2006). [PubMed: 16670086]

37. Boyman L et al. Calcium movement in cardiac mitochondria. Biophys J 107, 1289-1301, doi: 10.1016/j.bpj.2014.07.045 (2014). [PubMed: 25229137] 

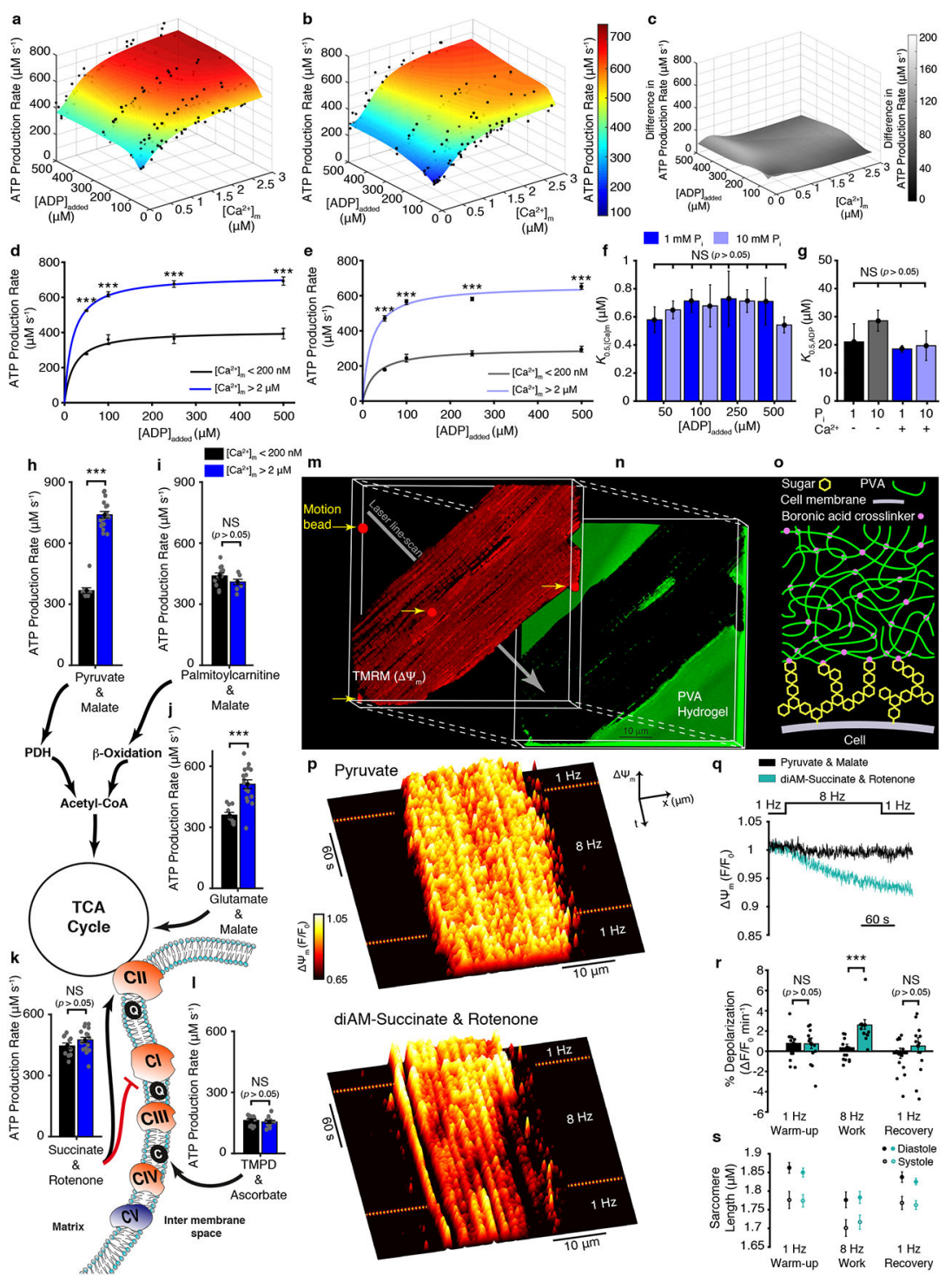

Figure 1. $\left[\mathrm{Ca}^{2+}\right]_{\mathrm{m}}$ sensitive ATP production by mitochondria.

a. The dependence of ATP production $(\mu \mathrm{M} / \mathrm{s})$ on $\left[\mathrm{Ca}^{2+}\right]_{\mathrm{m}}$ and $[\mathrm{ADP}]_{\text {added }}$ at $1 \mathrm{mM} \mathrm{Pi}(n=$ 37, 38, 38, 29 for 500, 250, 100, $50 \mu \mathrm{M}$ ADP added, respectively). b. Same as (a) but at 10 mM Pi ( $n=28,27,30,42$ for 500, 250, 100, $50 \mu \mathrm{M}$ ADP added, respectively). c. The difference in ATP production rates between $1 \mathrm{mM}$ Pi and $10 \mathrm{mM}$ Pi. d. Dependence of ATP production $(\mu \mathrm{M} / \mathrm{s})$ on ADP at $1 \mathrm{mM}$ Pi when $\left[\mathrm{Ca}^{2+}\right]_{\mathrm{m}}$ is $<200 \mathrm{nM}$ (black circles, $\mathrm{n}=3,3,3$, 5 for $50,100,250,500 \mu \mathrm{M}$ ADP added, respectively) or $>2 \mu \mathrm{M}$ (blue circles, $\mathrm{n}=8,7,6,9$ for 50,100, 250, $500 \mu \mathrm{M}$ ADP added, respectively). Data are fit to a Michaelis-Menten equation. e. Same as (d) but at $10 \mathrm{mM}$ Pi when $\left[\mathrm{Ca}^{2+}\right]_{\mathrm{m}}$ is $<200 \mathrm{nM}$ (grey circles, $\mathrm{n}=8,6,3$, 7 for 50, 100, 250, $500 \mu \mathrm{M}$ ADP added, respectively) or $2 \mu \mathrm{M}$ (light blue circles, $\mathrm{n}=5,7,5$, 5 for $50,100,250,500 \mu \mathrm{M}$ ADP added, respectively). Data are fit to Michaelis-Menten equation. f. $\left[\mathrm{Ca}^{2+}\right]_{\mathrm{m}}$ at which ATP production rate is half maximal $\left(K_{0.5,[\mathrm{Ca}] \mathrm{m}}\right)$ for [ADP $]_{\text {added }}$ at both 1 and $10 \mathrm{mM} \mathrm{P}_{\mathrm{i}}$. Each bar shows the $K_{0.5 \text {,[Ca]m }}$ constant of each of the eight fit lines shown as surface plots in $\mathbf{a}-\mathbf{b}\left(K_{0.5,[\mathrm{Ca}] \mathrm{m}} \pm\right.$ s.e. of fit in $\mu \mathrm{M}$, fitted sample size 
is given in $\mathbf{a}-\mathbf{b}$, individual data points shown in $\mathbf{a}-\mathbf{b})$. g. $[\mathrm{ADP}]_{\text {added }}$ at which ATP production is half maximal $\left(\mathrm{K}_{0.5, \mathrm{ADP}}\right)$ for $\left[\mathrm{Ca}^{2+}\right]_{\mathrm{m}}<100 \mathrm{nM}(-)$ and $>2 \mu \mathrm{M}(+)$ at both 1 and $10 \mathrm{mM} \mathrm{P}_{\mathrm{i}}$. Each bar shows the $K_{0.5, \mathrm{ADP}}$ constant of each of the four fit lines shown in d-e $\left(K_{0.5,[\mathrm{Ca}] \mathrm{m}} \pm\right.$ s.e. of fit in $\mu \mathrm{M}$, fitted sample size is given in d-e, individual data points shown in $\mathbf{a}-\mathbf{b})$. $\mathbf{h}-\mathbf{l}$. ATP production rate at low $\left[\mathrm{Ca}^{2+}\right]_{\mathrm{m}}\left(<200 \mathrm{~nm}\right.$, black bar) and high $\left[\mathrm{Ca}^{2+}\right]_{\mathrm{m}}(>2 \mu \mathrm{M}$, blue bar) using the indicated combination of carbon substrates and metabolic inhibitors $(\mathrm{n}=10$ 20 per group). Abbreviations used in the diagram: PDH, pyruvate dehydrogenase; TCA, tricarboxylic acid; CI, Complex 1; CII, Complex 2; CIII, Complex 3; CIV, Complex 4; CV, Complex 5 (i.e. ATP synthase); Q, ubiquinone; C, cytochrome c. m. 3D reconstruction of confocal Z-stack images of a cardiomyocyte loaded with the fluorescent indicator TMRM (tetramethylrhodamine methyl ester perchlorate, $50 \mathrm{nM}$ ). $\mathbf{n}$. The fluorescence of fluoresceincontaining poly(vinyl alcohol) (PVA) hydrogel that embeds the cell shown in (m). o. Diagram showing boronic acid crosslinker linking cell-surface sugars to the PVA hydrogel. p. Fluorescence surface plot demonstrating spatiotemporal changes of $\Delta \Psi_{\mathrm{m}}$. Measurements are done on cardiomyocyte paced by field-stimulation to contract at 1 or $8 \mathrm{~Hz}$ in a bath (extracellular) solution that contains top; pyruvate $(1 \mathrm{mM})$ and malate $(0.5 \mathrm{mM})$, or bottom; diAM-succinate (succinic acid diacetoxymethyl ester, $10 \mu \mathrm{M}$ ) and rotenone $(5 \mu \mathrm{M})$. q. Average $\Delta \Psi_{\mathrm{m}}$ fluorescence time course using pyruvate + malate (black, $\mathrm{n}=13$ cells) and diAM-succinate + rotenone (turquoise, $\mathrm{n}=12$ cells). $\mathbf{r}$. Quantification of $\Delta \Psi_{\mathrm{m}}$ depolarization expressed as percent change per minute. s. Sarcomere length measured simultaneously in the experiments shown in q. The sample size (n) in all panels represents the number of independent experiments. Data in $\mathbf{d}-\mathbf{e}, \mathbf{h}-\mathbf{l}$, and $\mathbf{r}-\mathbf{s}$ are mean \pm s.e.m. One-way two-tailed ANOVA with Bonferroni correction in $\mathbf{d - g}$, and two-sample two-tailed t-test in $\mathbf{h}-\mathbf{I}$ and $\mathbf{r} . * \mathrm{P}<0.05, * * \mathrm{P}<0.01$, *** $\mathrm{P}<0.001$. 

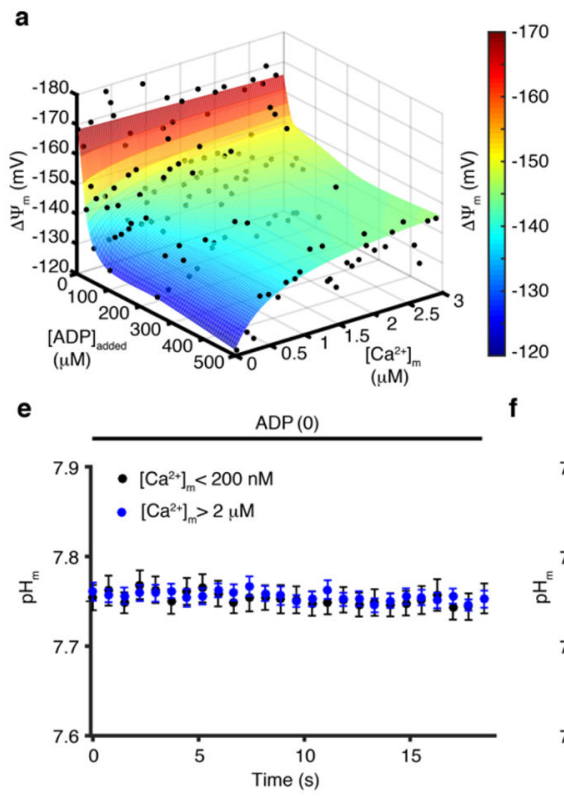
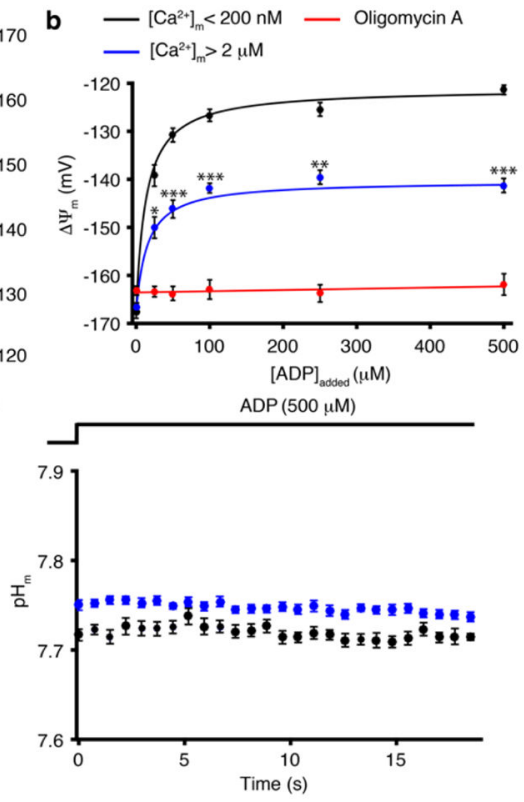

c d

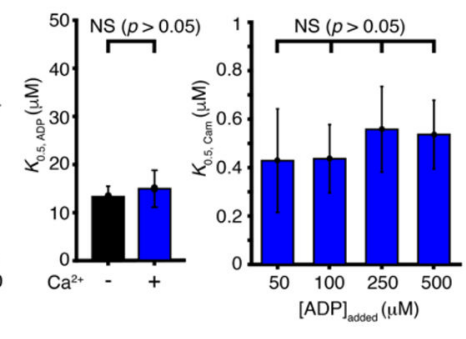

g

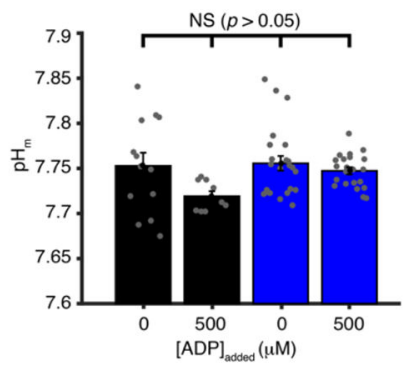

Figure 2. $\left[\mathrm{Ca}^{2+}\right]_{\mathrm{m}}$ control of $\Delta \Psi_{\mathrm{m}}$.

a. Steady-state $\Delta \Psi_{\mathrm{m}}$ is plotted as a function of $\left[\mathrm{Ca}^{2+}\right]_{\mathrm{m}}$ and $[\mathrm{ADP}]_{\mathrm{added}}(n=22,18,25,20$, 21,27 for $0,25,50,100,250,500 \mu \mathrm{M}[\mathrm{ADP}]_{\text {added }}$, respectively). b. Steady-state $\Delta \Psi_{\mathrm{m}}$ is plotted as a function of $[\mathrm{ADP}]_{\text {added }}$ when $\left[\mathrm{Ca}^{2+}\right]_{\mathrm{m}}$ is $<200 \mathrm{nM}$ (black circles, $\mathrm{n}=24,42,16$, $20,14,12$ for $0,25,50,100,250,500 \mu \mathrm{M}[\mathrm{ADP}]_{\mathrm{added}}$, respectively or is $>2 \mu \mathrm{M}$ (blue circles, $\mathrm{n}=15,6,11,5,6,10$ for $0,25,50,100,250,500 \mu \mathrm{M}[\mathrm{ADP}]_{\text {added }}$, respectively) or in the presence of $15 \mu \mathrm{M}$ Oligomycin A (red circles, $\mathrm{n}=12,18,17,18,18,14$ for $0,25,50$, $100,250,500 \mu \mathrm{M}[\mathrm{ADP}]_{\mathrm{added}}$, respectively). Data are fit to a Michaelis-Menten equation. c. $[\mathrm{ADP}]_{\text {added }}$ at which $\Delta \Psi_{\mathrm{m}}$ depolarization is half-maximal for $\left[\mathrm{Ca}^{2+}\right]_{\mathrm{m}}<200 \mathrm{~nm}(-)$ and $>2$ $\mu \mathrm{M}(+)$. Each bar shows the $K_{0.5}$, ADP constant of each of the two fit lines shown in $\mathbf{b}$ $\left(K_{0.5}\right.$, ADP \pm s.e. of fit in $\mu \mathrm{M}$, fitted sample size is given in $\mathbf{b}$, individual data points shown in a). d. $\left[\mathrm{Ca}^{2+}\right]_{\mathrm{m}}$ at which $\Delta \Psi_{\mathrm{m}}$ depolarization is half-maximal for $[\mathrm{ADP}]_{\mathrm{added}}$ of $50,100,250$ and $500 \mu \mathrm{M}$. Each bar shows the $K_{0.5}$, Cam constants of each of the four fits shown as surface plot in $\mathbf{a}\left(K_{0.5}\right.$, Cam \pm s.e. of fit in $\mu \mathrm{M}$, fitted sample size is given in $\mathbf{a}$, individual data points shown in a). e. The time-course of $\mathrm{pH}_{\mathrm{m}}$ (measured with the fluorescent indicator BCECF Methods and Extended Data Fig. 1) when $\left[\mathrm{Ca}^{2+}\right]_{\mathrm{m}}$ is $<200 \mathrm{nM}$ (black circles, $\mathrm{n}=13$ ), or $>2$ $\mu \mathrm{M}$ (blue circles, $\mathrm{n}=23$ ) in the absence of ADP. f. Same as (e) but in the presence of $500 \mu \mathrm{M}$ ADP (black circles, $n=9$, blue circles, $n=22)$. g. Quantification of $\mathrm{pH}_{\mathrm{m}}$ in e-f $(\mathrm{n}=13,9,23$, 22). The sample size (n) in all panels represents the number of independent experiments. Data in $\mathbf{b}$, and $\mathbf{e - g}$ are mean \pm s.e.m. One-way two-tailed ANOVA with Bonferroni correction in $\mathbf{b}, \mathbf{d}, \mathbf{g}$ and two-sample two-tailed t-test in $\mathbf{c} . * \mathrm{P}<0.05$, ** $\mathrm{P}<0.01, * * *$ $\mathrm{P}<0.001$. 

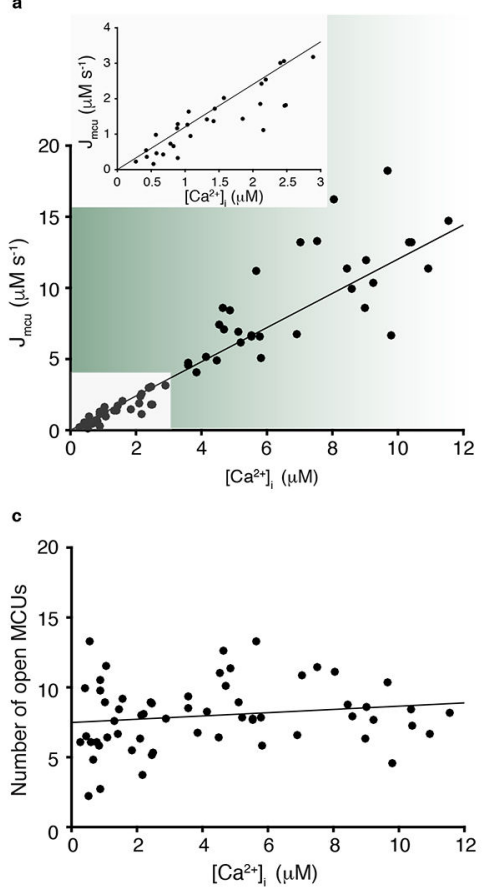

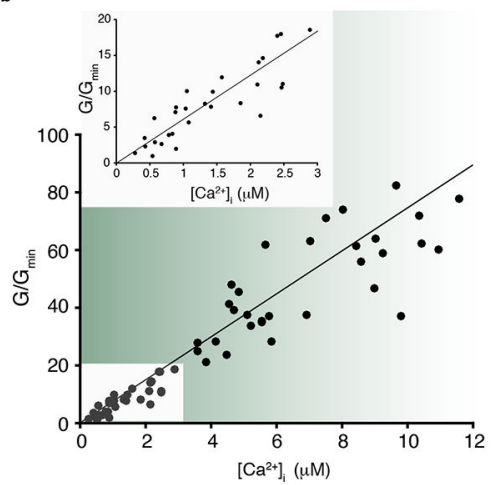

d

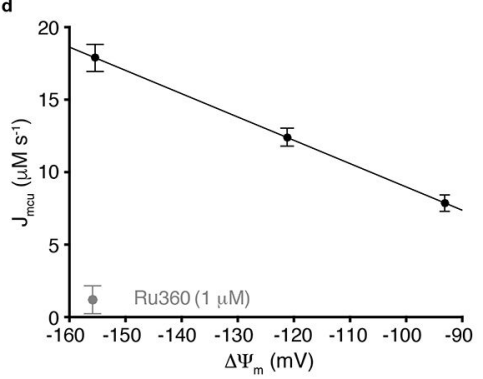

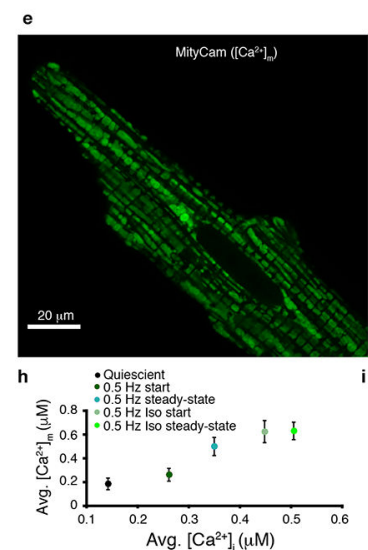

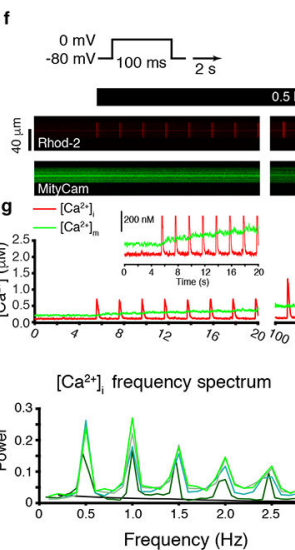

Isoproterenol (500 nM)
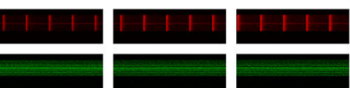

Figure 3. $\left[\mathrm{Ca}^{2+}\right]_{m}$ dynamics and $\mathrm{MCU} \mathrm{Ca}{ }^{2+}$ conductance.

a. Stopped-flow measurement of the MCU-dependent $\mathrm{Ca}^{2+}$ influx $\left(\mathrm{J}_{\mathrm{mcu}}\right)$ scaled to a liter of cytosol (see Methods and $\left.\operatorname{ref}^{7}\right)$. $\mathrm{J}_{\mathrm{mcu}}\left(\mu \mathrm{M} \cdot \mathrm{s}^{-1}\right)$ is plotted as a function of measured $\left[\mathrm{Ca}^{2+}\right]_{\mathrm{i}}$ $\left(\mathrm{n}=63\right.$ independent experiments, each with $\left[\mathrm{Ca}^{2+}\right]_{\mathrm{i}},\left[\mathrm{Ca}^{2+}\right]_{\mathrm{m}}$ and $\Delta \Psi_{\mathrm{m}}$ measured). Inset shows zoomed-in region between 0 and $3 \mu \mathrm{M}\left[\mathrm{Ca}^{2+}\right]_{\mathrm{i}}$. Linear least-squares fit to the filled circles is shown (slope $=1.2$.). Stopped-flow data are shown in Extended Data Fig. 6. $\mathbf{b}$. MCU conductance $(\mathrm{G})$ for each of 63 experiments shown in (a) normalized to the minimal conductance $\left(\mathrm{G}_{\mathrm{min}}\right)$ of each dataset $\left(\mathrm{G} / \mathrm{G}_{\mathrm{min}}\right)$ plotted as a function of $\left[\mathrm{Ca}^{2+}\right]_{i}$ where $\mathrm{G}=$ $\mathrm{J}_{\mathrm{mcu}} \mathrm{C} * 10^{-6} /\left(\Delta \Psi_{\mathrm{m}} * 10^{-3}-(\mathrm{RT} / 2 \mathrm{~F}) * \ln \left(\left[\mathrm{Ca}^{2+}\right]_{\mathrm{i}} /\left[\mathrm{Ca}^{2+}\right]_{\mathrm{m}}\right)\right.$, (see Methods). Inset shows zoomedin region between 0 and $3 \mu \mathrm{M}\left[\mathrm{Ca}^{2+}\right]_{\mathrm{i}}$. Linear least-squares fit line to the filled circles is shown (slope $=6.1$ ). c. Number of open MCUs per mitochondrion $\left(\mathrm{NP}_{\mathrm{o}}\right)$ plotted as a function of $\left[\mathrm{Ca}^{2+}\right]_{\mathrm{i}}$. Taken from (b) after dividing by the number of mitochondria per liter cytosol (see Methods) and dividing by the $\left[\mathrm{Ca}^{2+}\right]_{\mathrm{i}}$-dependent unitary conductance of $\mathrm{MCU}^{7,18}$. Linear least-squares fit to the filled circles is shown $($ slope $=0.116$, intercept $=$ 
7.48). d. MCU Ca ${ }^{2+}$ influx $\left(\mathrm{J}_{\mathrm{mcu}}, \mu \mathrm{M} \cdot \mathrm{s}^{-1}\right)$ plotted as a function of $\Delta \Psi_{\mathrm{m}} \cdot\left[\mathrm{Ca}^{2+}\right]_{\mathrm{i}}$ and $\Delta \Psi_{\mathrm{m}}$ were measured as in (a) but using a multi-well plate reader. $\Delta \Psi_{\mathrm{m}}$ was set by using a $\mathrm{K}^{+}$ gradient and the $\mathrm{K}^{+}$ionophore valinomycin (see Methods and Fig. 4 ). $\left[\mathrm{Ca}^{2+}\right]_{\mathrm{i}}$ was set to 15 $\mu \mathrm{M}\left(\mathrm{n}=4,7,4\right.$ independent experiments for $\Delta \Psi_{\mathrm{m}}=-155,-122,-92 \mathrm{mV}$ groups, respectively). MCU blocker Ru360 $(1 \mu \mathrm{M})$ reduced $\mathrm{J}_{\mathrm{MCU}}$ to near zero ( $\mathrm{n}=6$ independent experiments). Data are mean \pm s.e.m. e. Deconvolved Airyscan confocal image showing the fluorescence of the mitochondrially-targeted $\mathrm{Ca}^{2+}$-sensor MityCam expressed in a cardiomyocyte. Note distinct MityCam localization in individual mitochondria. f. Confocal line-scan images from a cardiomyocyte expressing MityCam; top panels show the fluorescence of Rhod-2 (tripotassium salt, loaded via the patch-clamp pipette); lower panels show MityCam fluorescence. To stimulate $\left[\mathrm{Ca}^{2+}\right]_{\mathrm{i}}$ transients the membrane potential is stepped repeatedly from a holding level of $-80 \mathrm{mV}$ to $0 \mathrm{mV}$ every 2 seconds. Isoproterenol $(500 \mathrm{nM})$ is applied at the times indicated. Note that $\mathrm{Ca}^{2+}$ binding reduces the fluorescence of MityCam. g. The time-course of changes in $\left[\mathrm{Ca}^{2+}\right]_{\mathrm{i}}$ and $\left[\mathrm{Ca}^{2+}\right]_{\mathrm{m}}$ from the respective fluorescence measurements shown in panel $f$. The experiments shown in panels e-j were repeated independently with similar results $(\mathrm{n}=9$ cells $) . \mathbf{h}$. Time-averaged $\left[\mathrm{Ca}^{2+}\right]_{\mathrm{m}}$ vs. timeaveraged $\left[\mathrm{Ca}^{2+}\right]_{i}(n=9$ cells). Data are mean \pm s.e.m. $\mathbf{i}-\mathbf{j}$. Fast Fourier transform showing the frequency composition of $\left[\mathrm{Ca}^{2+}\right]_{\mathrm{i}}$ and $\left[\mathrm{Ca}^{2+}\right]_{\mathrm{m}}$ signals $(\mathrm{n}=9$ cells). 
a

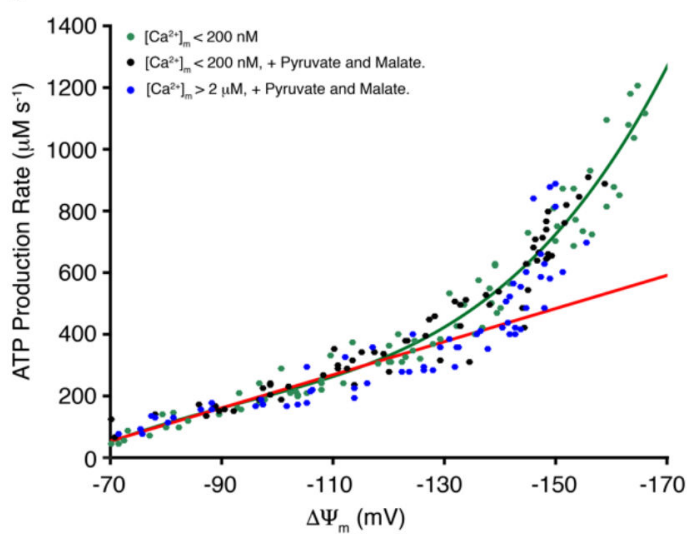

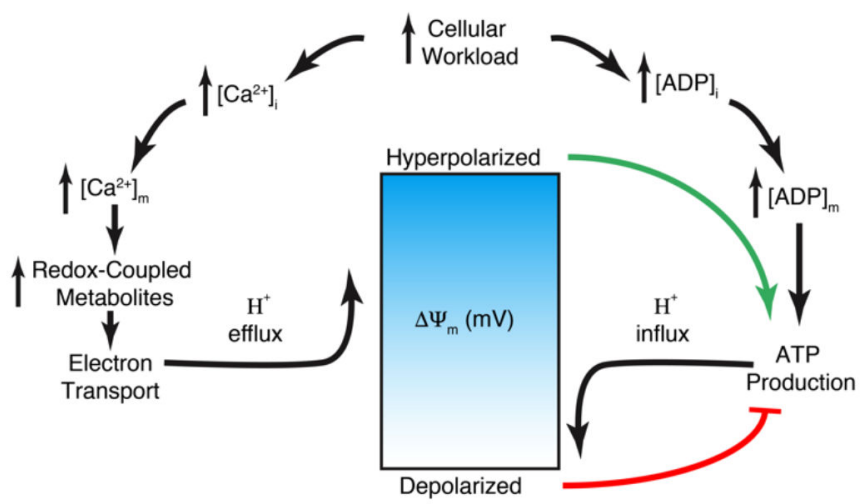

Figure 4. $\Delta \Psi_{m}$ control of ATP production.

a. The dependence of ATP production $(\mu \mathrm{M} / \mathrm{s})$ on $\Delta \Psi_{\mathrm{m}}$ in the absence of carbon substrate and at $\left[\mathrm{Ca}^{2+}\right]_{\mathrm{m}}<200 \mathrm{nM}$ (green circles, $n=77$ independent experiments), or with Pyruvate and Malate at $\left[\mathrm{Ca}^{2+}\right]_{\mathrm{m}}<200 \mathrm{nM}$ (black circles, $n=72$ independent experiments), or with Pyruvate and Malate at $\left[\mathrm{Ca}^{2+}\right]_{\mathrm{m}}>2 \mu \mathrm{M}$ (blue circles, $n=65$ independent experiments). $\Delta \Psi_{\mathrm{m}}$ was set by using a fixed $\mathrm{K}^{+}$gradient and the $\mathrm{K}^{+}$ionophore valinomycin (see Methods). The green line is an empirical fit to the data and the red line corresponds to expected ATP production based on linear changes in driving force $\left(\Delta G_{\text {drive }}\right)$, where ATP production rate $=$ $k \bullet \Delta G_{\text {drive }}$ and the kinetic coefficient $(k)$ is assumed to be constant (see Supplementary Information section 1.1 for more details). b. Proposed model for voltage-energized $\mathrm{Ca}^{2+}-$ sensitive ATP production. In this physiological feedback mechanism, mitochondrial ATP production is tuned to cellular ATP consumption by cellular $\mathrm{Ca}^{2+}$ signals and ADP availability. Both $\left[\mathrm{Ca}^{2+}\right]_{\mathrm{i}}$ and $[\mathrm{ADP}]_{\mathrm{i}}$ rise during an increase in workload but have opposing effects on $\Delta \Psi_{\mathrm{m}}$. A rise in cytosolic [ADP] increases ADP availability to ATP synthase, which couples ATP production to influx of $\mathrm{H}^{+}$into the mitochondrial matrix. A rise in $\left[\mathrm{Ca}^{2+}\right]_{\mathrm{i}}$ increases $\left[\mathrm{Ca}^{2+}\right]_{\mathrm{m}}$ to stimulate the production of redox-coupled metabolites that provide energy for the electron transport chain (ETC) to pump protons $\left(\mathrm{H}^{+}\right)$out of the mitochondrial matrix. The dynamic balance of $\mathrm{H}^{+}$influx by ATP synthase and $\mathrm{H}^{+}$efflux by the ETC sets $\Delta \Psi_{\mathrm{m}}$, which in the presence of $\left[\mathrm{Ca}^{2+}\right]_{\mathrm{m}}$ will be hyperpolarized, thus, energizing ATP production by ATP synthase. 